\title{
Some issues in uncertainty quantification and parameter tuning: a case study of convective parameterization scheme in the WRF regional climate model
}

\author{
B. Yang ${ }^{1,2}$, Y. Qian ${ }^{1}$, G. Lin ${ }^{1}$, R. Leung ${ }^{1}$, and Y. Zhang ${ }^{2}$ \\ ${ }^{1}$ Pacific Northwest National Laboratory, Richland, Washington, USA \\ ${ }^{2}$ School of Atmospheric Sciences, Nanjing University, Nanjing, China \\ Correspondence to: Y. Qian (yun.qian@pnnl.gov)
}

Received: 10 November 2011 - Published in Atmos. Chem. Phys. Discuss.: 2 December 2011

Revised: 7 February 2012 - Accepted: 21 February 2012 - Published: 5 March 2012

\begin{abstract}
The current tuning process of parameters in global climate models is often performed subjectively or treated as an optimization procedure to minimize model biases based on observations. While the latter approach may provide more plausible values for a set of tunable parameters to approximate the observed climate, the system could be forced to an unrealistic physical state or improper balance of budgets through compensating errors over different regions of the globe. In this study, the Weather Research and Forecasting (WRF) model was used to provide a more flexible framework to investigate a number of issues related uncertainty quantification (UQ) and parameter tuning. The WRF model was constrained by reanalysis of data over the Southern Great Plains (SGP), where abundant observational data from various sources was available for calibration of the input parameters and validation of the model results. Focusing on five key input parameters in the new Kain-Fritsch (KF) convective parameterization scheme used in WRF as an example, the purpose of this study was to explore the utility of high-resolution observations for improving simulations of regional patterns and evaluate the transferability of UQ and parameter tuning across physical processes, spatial scales, and climatic regimes, which have important implications to UQ and parameter tuning in global and regional models. A stochastic importance sampling algorithm, Multiple Very Fast Simulated Annealing (MVFSA) was employed to efficiently sample the input parameters in the KF scheme based on a skill score so that the algorithm progressively moved toward regions of the parameter space that minimize model errors.
\end{abstract}

The results based on the WRF simulations with $25-\mathrm{km}$ grid spacing over the SGP showed that the precipitation bias in the model could be significantly reduced when five optimal parameters identified by the MVFSA algorithm were used. The model performance was found to be sensitive to downdraftand entrainment-related parameters and consumption time of Convective Available Potential Energy (CAPE). Simulated convective precipitation decreased as the ratio of downdraft to updraft flux increased. Larger CAPE consumption time resulted in less convective but more stratiform precipitation. The simulation using optimal parameters obtained by constraining only precipitation generated positive impact on the other output variables, such as temperature and wind. By using the optimal parameters obtained at $25-\mathrm{km}$ simulation, both the magnitude and spatial pattern of simulated precipitation were improved at $12-\mathrm{km}$ spatial resolution. The optimal parameters identified from the SGP region also improved the simulation of precipitation when the model domain was moved to another region with a different climate regime (i.e. the North America monsoon region). These results suggest that benefits of optimal parameters determined through vigorous mathematical procedures such as the MVFSA process are transferable across processes, spatial scales, and climatic regimes to some extent. This motivates future studies to further assess the strategies for UQ and parameter optimization at both global and regional scales.

\section{Introduction}

Sound strategies and decisions making in climate change mitigation and adaptation require not only robust projections of the mean or most likely scenario but also the occurrence of 
low probability but high-impact events (IPCC, 2007). Uncertainty quantification (UQ) is the science of quantitative characterization and reduction of uncertainties in applications. It determines how likely certain outcomes are if some aspects of the system are not exactly known. UQ of predicted future climate is usually based on the ability of models to produce the current climate (Allen et al., 2000; Tebaldi et al., 2005). The full probability density functions (PDFs) of occurrence for both present climate and future prediction are needed to predict the probability of extreme weather or climate events.

Different approaches have been applied to generate ensemble simulations and construct PDFs for variables of climate model output. These approaches include perturbing the initial conditions, perturbing the input parameters of the model, ensemble simulations with multiple parameterization schemes, or ensemble simulations with multiple models, and so on (Allen et al., 2000; Giorgi and Mearns, 2002; Stainforth et al., 2005; Lopez et al., 2006). Covey et al. (2011) found that the variability of globally averaged upwelling longwave radiation and surface temperature induced by perturbation of initial condition is much smaller than that induced by perturbation of model input parameters. Hawkins and Sutton (2009) estimated the contributions to the total climate change prediction uncertainty from internal variability, model uncertainty, and scenario uncertainty and found that their relative contributions depend on the prediction lead times. Furthermore, for the decadal time scales and regional spatial scales $(\sim 2000 \mathrm{~km})$, model uncertainty is of greater importance than internal variability. Quantifying and reducing the uncertainty of tunable input parameters in climate models can improve our understanding of the physical process in climate systems as well as reduce the uncertainty for projecting future climate change.

Parameterizations in climate models typically contain many input parameters that are determined based on the physical processes being parameterized or estimated based on tuning to obtain qualitative agreement between the simulations and observations from limited local measurements or global observations. Larger number or ranges of input parameters usually result in higher uncertainties in climate simulations because of nonlinear interactions and compensating errors of parameters (Gilmore et al., 2004; Molders, 2005; Min et al., 2007; Murphy et al., 2007). Perturbed-Parameter Ensembles (PPE) with the same climate model but different combinations of several key input parameters, within reasonable ranges, have been employed to assess future climate uncertainty (Murphy et al., 2004; Jackson et al., 2003, 2008; Collins et al., 2011).

To approximate the posterior probability distribution of input parameters in physical parameterizations, many sampling strategies have been proposed, such as grid search method, Metropolis/Gibbs algorithm (Metropolis et al., 1953; Kirkpatrick et al., 1983; Sen and Stoffa, 1996), Monte Carlo or Quasi Monte Carlo (QMC), (Moskowitz and Caflisch, 1996), Latin Hypercube selection (Stein, 1987), Multiple Very Fast
Simulated Annealing (MVFSA) (Ingber, 1989; Jackson et al., 2004), among others (Tierney and Mira, 1999; Haario et al., 2001). Grid search is a straightforward method to test the sensitivity of parameters by subdividing each parameter space into equally spaced intervals and evaluating uncertainty arising from those combinations. However, this method may require huge computational resources. For example, around $10^{5}$ simulations are needed if five parameters with 10 intervals for each parameter are to be explored. Thus, high-efficiency sampling methods are needed for applications related to climate modeling. MVFSA is a stochastic importance sampling algorithm that can progressively move toward regions of the parameter space that minimize model errors and more efficiently provide useful information for optimizing or generating accurate measures of the posterior distribution (Villagran et al., 2008). Jackson et al. (2008) applied MVFSA to optimize six parameters related to the cloud process in a Global Climate Model (GCM) because cloud processes play a critical role in the hydrological cycle and uncertainty of climate response to doubling of $\mathrm{CO}_{2}$ forcing (Colman, 2003; Webb et al., 2006; Medeiros and Stevens, 2011). Constrained by different sets of observations, their work provided a six-member ensemble of optimized model configurations with a narrower range of future temperature change projection.

Currently, UQ and parameter tuning in climate study are typically applied in GCMs, with more focus on global climate sensitivity and large-scale climatic features. Equal weighting of the state fidelity globally could compromise parameter tuning in GCMs because the processes being tuned may only be relevant for particular regimes. Furthermore, global tuning may produce parameter settings that approximate the observed global climate, but at the expense of yielding unphysical states or improper balance of budgets at the local or regional scales. Even if the calibration produces realistic regional means, important spatial variability may not be reproduced if observed spatial patterns from high-resolution measurements are not utilized in the global tuning. Hacker et al. (2011) evaluated the impacts of initial condition and model parameterization uncertainties on a WRF-based ensemble prediction system and found that different combinations of parameterization schemes associated with perturbed parameters could generate the most skillful ensemble prediction.

This study applies UQ and parameter tuning to a Regional Climate Model (RCM), which offers more flexibility in terms of model configuration and is computationally more economical, allowing some of the above issues to be explored in more details. More specifically, we explore the utility of high-resolution observations for improving simulations of regional patterns. We further investigate three important questions. First, can calibration of specific physical parameterizations lead to improvements in aspects not directly influenced by the parameterizations? Second, can model calibration performed at a coarser scale improve simulations at 
a finer scale? Lastly, can optimal parameters obtained by calibration in one climate regime lead to improvements in other climate regimes? These questions aim at evaluating the transferability of UQ and parameter tuning across physical processes, spatial scales, and climatic regimes, which have important implications to UQ and parameter tuning in global and regional models.

With the rapid growth of computing resources in the past decades, some climate models can now be applied at a cloud-resolving scale (Khairoutdinov et al., 2001; Tao et al., 2009). However, because of simulation length and the need for ensemble modeling, climate models being used in projecting climate change still use grid spacing of $25 \mathrm{~km}$ or larger where cumulus processes have to be parameterized. Since convective process contributes disproportionately to the magnitude and intensity of precipitation, and the diabatic heating from convective process is an important driver of global and regional circulation, it is important to better understand and constrain the convective parameterizations used in climate and weather forecasting models (Warner and Hsu, 2000; Liu et al., 2001). Many different Convective Parameterization Schemes (CPS) have been developed over the past decades (Janjic, 1994; Emanuel and Zivkovic-Rothman, 1999; Gregory et al., 2000; Grell and Devenyi, 2002). Among them, the Kain-Fritsch (KF) scheme (Kain and Fritsch, 1993; Bechtold et al., 2001), including more recent updates (Kain, 2004), is commonly used in regional models including the Weather Research and Forecasting (WRF) model (Skamarock et al., 2001).

This study applies UQ and model calibration to the WRF regional model to address the questions discussed above. Simulations were performed with WRF constrained by reanalysis data over the Southern Great Plains (SGP), where abundant observational data from various sources are available for calibration of the input parameters and validation of the model results. The MVFSA importance sampling algorithm was applied to quantify the uncertainty ranges and identify the optimal values of five key input parameters in the new KF CPS used in the WRF model. Because of its importance and sensitivity to model physics, precipitation is used as the constrained variable in the optimization process. The impact of precipitation-based optimization on a few other variables, such as temperature and wind, was analyzed. Furthermore, parameter transferability across spatial scales and climate regimes was investigated using sensitivity experiments.

This paper is organized as follows. Parameter selection in the new KF CPS, the MVFSA sampling algorithm, observational data, and the WRF model configuration are described in Sect. 2 and the optimization results, sensitivities of model performance, precipitation and other output variables to parameters in the KF scheme, and dependence of optimization on model configurations are presented in Sect. 3. The conclusion is discussed in the last section.

\section{Parameters, approach and experiment design}

\subsection{The new KF CPS and five key parameters}

CPSs are appropriate for use in RCMs with a moderate grid spacing of $10-100 \mathrm{~km}$. This spacing is large enough so that a cloud ensemble within the grid can be treated as a statistical entity but small enough to keep the uniform characteristics of the cloud environment. The new KF CPS, which is commonly used in many mesoscale models including WRF, was developed based on a mass flux parameterization (Kain, 2004). Using a Lagrangian parcel method (Simpson and Wiggert, 1969; Kreitzberg and Perkey, 1976), the new KF CPS operates by searching for the Updraft Source Layer (USL), which has a potential for inducing shallow or deep convection, starting from the surface upward to within the lowest $300 \mathrm{hPa}$ of the atmosphere. When the USL is identified, updraft flux is initialized with a velocity based on atmospheric instability and grid-scale vertical motion at USL (Kain and Fritsch, 1990). Air mass is exchanged between the updraft and the environment through entrainment and detrainment at each layer. The rate of entrainment flux is related to the cloud radius that varies from 1000 to $2000 \mathrm{~m}$ depending on the large-scale vertical velocities. The intensity of updraft flux decreases with altitude as the thermal contrast between the cloud and the environment is reduced by mixing. Convective downdrafts, which play an essential role in determining the heating profile and humidity features in the lower troposphere (Johnson, 1976; Cheng, 1989), are driven by the evaporation of condensate generated within the updrafts. The strength of the downdraft mass flux is related to the relative humidity of environmental air (Knupp and Cotton, 1985; Ferrier et al., 1996; Shepherd et al., 2001). The fluxes of updraft, entrainment/detrainment, downdraft, as well as of grid-scale compensating subsidence are parameterized and used to calculate the convective temperature, water vapor and cloud water tendencies that are used to advance the respective largescale fields.

Five key parameters related to the downdraft flux rate and starting height, environmental entrainment flux rate, turbulent kinetic energy (TKE) in the sub-cloud layer, and the consumption time of Convective Available Potential Energy (CAPE) in the new KF CPS in the WRF are thought to be important in the KF CPS, but the range of their possible values is quite wide (J. Kain, personal communications, 2011).

The intensities of both downdraft and entrainment fluxes are proportional to the updraft mass flux at the top of USL in the KF CPS. In this study, two parameters $P_{\mathrm{d}}$ and $P_{\mathrm{e}}$ are defined as additional scale factors to modulate the rates of downdraft and entrainment fluxes from $1 / 2$ to 2 times of their original values, respectively.

$\frac{M_{\mathrm{d}}^{\mathrm{USL}}}{M_{\mathrm{u}}^{\mathrm{USL}}}=2 \times(1-\mathrm{RH}) \times 2^{P_{\mathrm{d}}}, P_{\mathrm{d}} \in(-1,1)$, 
$\frac{\delta M_{\mathrm{e}}}{M_{\mathrm{u}}^{\mathrm{USL}}}=\frac{-0.03 \times \delta p}{R} \times 2^{P_{\mathrm{e}}}, P_{\mathrm{e}} \in(-1,1)$.

In Eqs. (1) and (2), $M_{\mathrm{u}}^{\mathrm{USL}}$ and $M_{\mathrm{d}}^{\mathrm{USL}}$ are the updraft and downdraft mass fluxes at the top of USL, respectively. RH is the mean relative humidity of environment air from the starting layer of downdraft to cloud base. $R$ is the cloud radius, $\delta p$ is the pressure thickness of a model layer and $\delta M_{\mathrm{e}}$ is the maximum possible entrainment rate of this layer. More details can be found in Kain and Fritsch (1990).

Downdraft is assumed to start from $150 \mathrm{hPa}$ above USL in the standard KF CPS. The starting height of downdraft $P_{\mathrm{h}}$ controls the downdraft structures and also affects the atmospheric properties in the sub-cloud layer. We set the range of $P_{\mathrm{h}}$ as $50-350 \mathrm{hPa}$ to allow a larger degree of freedom in the downdraft structures from tall and narrow to short and wide.

Shallow or deep convection are based on different closure assumptions. For shallow convection, the intensity of updraft mass flux at USL is assumed to be a function of TKE in the sub-cloud layer. For deep convection, the KF scheme incrementally rearranges the updraft, downdraft and other mass flux until the CAPE is reduced by at least $90 \%$ within a specified time, called CAPE consumption time. The CAPE consumption time is related to the vertical shear defined as the difference between horizontal wind at the cloud base and $500 \mathrm{hPa}$ level (Bechtold et al., 2001). The TKE and average CAPE consumption time are referred to as $P_{\mathrm{t}}$ and $P_{\mathrm{c}}$, with values of $5 \mathrm{~m}^{2} \mathrm{~s}^{-2}$ and $2700 \mathrm{~s}$ in the standard KF CPS. We allowed a range from 3 to $12 \mathrm{~m}^{2} \mathrm{~s}^{-2}$ for $P_{\mathrm{t}}$ and from 900 to $7200 \mathrm{~s}$ for $P_{\mathrm{c}}$. The default value in the standard KF scheme and range of value for each parameter are shown in Table 1.

\subsection{MVFSA optimization approach}

Very Fast Simulated Annealing (VFSA) is a stochastic importance sampling algorithm with high converging efficiency toward the optimal results (Ingber, 1989; Jackson et al., 2004). For most optimization applications, multiple extreme values (i.e. local minimum/maximum) may exist and the selected parameter values may be trapped by some local minimums within the parameter space in one VFSA procedure. Repeating the VFSA multiple times with different initial starting parameter set (i.e. MVFSA) can help prevent such local trapping and identify the global minimum (Jackson et al., 2008; Villagran et al., 2008). The steps in the MVFSA algorithm, which is adapted from Jackson et al. (2004, 2008), are the following;

1. Take random points in the parameter spaces and run a simulation at each step. At the first step, an initial starting parameter set $\left(\boldsymbol{m}^{0}\right)$ is randomly selected to run the first WRF simulation.

2. Quantify the differences between simulation and observation in terms of a scalar skill score or "cost," referred to as $E(\boldsymbol{m})$, where $\boldsymbol{m}$ is the parameter set. If Gaussian errors exist in the model results, $E(\boldsymbol{m})$ is usually defined as

$$
E(\boldsymbol{m})=\sum_{i=1}^{N} \frac{1}{2 N}\left\{\left[\mathbf{d}_{\mathrm{obs}}-\mathbf{g}(\boldsymbol{m})\right]^{T} \times \mathbf{C}^{-1}\left[\mathbf{d}_{\mathrm{obs}}-\mathbf{g}(\boldsymbol{m})\right]\right\}_{i} .
$$

$N$ refers to different sets of observations/variables. $\mathbf{d}_{\text {obs }}$ refers to observations and $\mathbf{g}(\boldsymbol{m})$ refers to simulations with a specific parameter set $\boldsymbol{m}$. $\mathbf{C}^{-1}$ is the inverse of the data covariance matrix, which could include a weight coefficient for different variables. In this study, only one set of observation (precipitation) is used with equal weight at each grid point in the observation constraint in Eq. (3), so $E(\boldsymbol{m})$ is simplified as:

$$
\begin{aligned}
E(\boldsymbol{m}) & =\left\{\sum_{k=1}^{K} \sum_{i=1}^{I} \sum_{j=1}^{J}\left[d_{\mathrm{obs}, i j k}-g_{i j k}(\boldsymbol{m})\right]^{2} / C_{i j k}\right\} / \\
(I \times J \times K) &
\end{aligned}
$$

where $i, j$ are the horizontal grid points in the model domain, and $k$ represents the number of time steps. In Eq. (4), the model biases are assumed to be spatially or temporally uncorrelated (i.e. the data covariance matrix $\mathbf{C}^{-1}$ in Eq. (3) only contains nonzero elements along the diagonal). The frequency of precipitation rate tends to have an exponential distribution rather than a Gaussian distribution, which indicates that the score function of the model based on Eqs. (3) and (4) is dominated by the upper range in the observation. Given that our case study has strong convection over a limited region during a short time period, the use of Eq. (4) is appropriate in this study (see Sect. 2.3).

3. Reselect the parameter values based on the skill score so that the algorithm progressively moves toward regions of the parameter space that minimize modeling errors. Starting from the second round of the procedure, the parameters will be perturbed to a new set of $\boldsymbol{m}^{\text {new }}$ as follows:

$$
\begin{aligned}
& m_{i}^{\text {new }}=m_{i}^{0}+y_{i}\left(m_{i}^{\max }-m_{i}^{\min }\right), \\
& y_{i} \in(-1,1), \\
& m_{i}^{\text {min }} \leq m_{i}^{\text {new }} \leq m_{i}^{\max },
\end{aligned}
$$

where $m_{i}^{\min }$ and $m_{i}^{\max }$ represent the possible minimum and maximum values of each parameter, and $y_{i}$ is drawn from a Cauchy distribution which is dependent on an annealing coefficient $T$ :

$$
y_{i}=\operatorname{sgn}(\mathrm{RND}-0.5) T_{k}\left[\left(1+\frac{1}{T_{k}}\right)^{|2 \mathrm{RND}-1|}-1\right] .
$$


Table 1. The short name, default, minimum and maximum values, and the descriptions of the five parameters in the KF convective parameterization scheme in WRF 3.2.1.

\begin{tabular}{lrrrl}
\hline Parameter & Default & Minimum & Maximum & Description \\
\hline$P_{\mathrm{d}}$ & 0 & -1 & 1 & coefficient related to downdraft mass flux rate \\
$P_{\mathrm{e}}$ & 0 & -1 & 1 & coefficient related to entrainment mass flux rate \\
$P_{\mathrm{h}}$ & 150 & 50 & 350 & starting height of downdraft above USL (hPa) \\
$P_{\mathrm{t}}$ & 5 & 3 & 12 & maximum TKE in sub-cloud layer $\left(\mathrm{m}^{2} \mathrm{~s}^{-2}\right)$ \\
$P_{\mathrm{c}}$ & 2700 & 900 & 7200 & average consumption time of CAPE (s) \\
\hline
\end{tabular}

Within Eqs. (5)-(8), subscript $i, k$ are the parameter number and iteration number, respectively. sgn is the sign operator and RND represents a random number from a uniform distribution between 0 and 1 . At iteration $k$, the annealing coefficient $T$ is lowered according to

$T_{k}=T_{0} \exp \left[-0.9 \times(k-1)^{1 / 2}\right]$.

If the results with a new set of parameters show an improvement over the old one, in effect, $\Delta E=E\left(\boldsymbol{m}^{\text {new }}\right)-$ $E\left(\boldsymbol{m}^{0}\right)<0$, then the new set of $\boldsymbol{m}$ is accepted as the basis for the next iteration, that is, $\boldsymbol{m}^{0}=\boldsymbol{m}^{\text {new }}$. If not, the new set of parameters can still possibly be accepted with a probability

$P=\exp \left(\frac{-\Delta E}{T_{k}}\right)$.

With a lower $T$, the VFSA algorithm moves progressively toward regions of the parameter space that minimize model errors since the width of the Cauchy distribution will be incrementally focused on the current accepted parameter set, facilitating the VFSA algorithm to converge more efficiently. In this study, we lower $T$ every two steps with an initial value of $T_{0}$ as 10 .

4. To get global optimal values, we repeat the VFSA procedure three times with different starting parameter set (i.e. three chains). We conducted 50 experiments in each chain. Only 148 simulations are valid because instability occurred in two of the simulations. The three chains nearly converge to the same region within the parameter spaces (not shown), indicating that three chains are probably enough for this case study.

Figure 1 shows the best values averaged for three iterations based on three independent MVFSA chains. As seen in Fig. 1, the averaged best values monotonically decrease as the number of model integrations increases and finally reach convergence after 28 integrations.

In climate model calibration, we are interested in not only the magnitudes of model bias (e.g. standard deviation) but

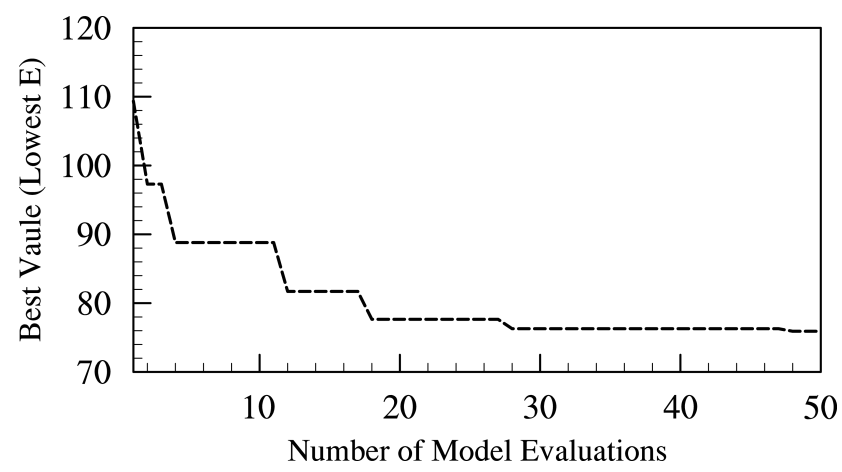

Fig. 1. The best values obtained using MVFSA method as a function of the number of model evaluations.

also the similarity of spatial pattern (e.g. spatial correlation coefficient) between observed and modeled large-scale fields (Taylor, 2001). We define

$C(\boldsymbol{m})=\sum_{n=1}^{N} \mathrm{SC}\left[\mathbf{d}_{\mathrm{obs}, n}, \mathbf{g}_{n}(\boldsymbol{m})\right] / N$,

where $\mathrm{SC}\left[\mathbf{d}_{\mathrm{obs}}, \mathbf{g}(\boldsymbol{m})\right]$ refers to the spatial correlation coefficient between the observation and simulation, and $n$ represents the time series. Both $E(\boldsymbol{m})$ and $C(\boldsymbol{m})$ are normalized so they can be considered together as $E C(\boldsymbol{m}), E C(\boldsymbol{m})=E(\boldsymbol{m})$ $-C(\boldsymbol{m})$. Doing so accounts for both the magnitude of bias and similarity of spatial pattern. For brevity, $E(\boldsymbol{m}), C(\boldsymbol{m})$ and $E C(\boldsymbol{m})$ are denoted as $E, C$, and $E C$, respectively hereafter.

The University of Washington (UW) 1/8 gridded meteorological data set includes daily precipitation, maximum and minimum 2-m temperature and $10-\mathrm{m}$ wind speed (Maurer et al., 2002). Only the daily precipitation data are used in the observation constraint in Eq. (4). The maximum and minimum temperatures at 2-m height and wind speed at 10$m$ height are used to evaluate the WRF simulation performances that used the optimal parameters derived by constraining the precipitation alone.

\subsection{Model configuration}

The Advanced Research Weather Research and Forecasting model Version 3.2.1 (WRF Version 3.2.1, Skamarock et 


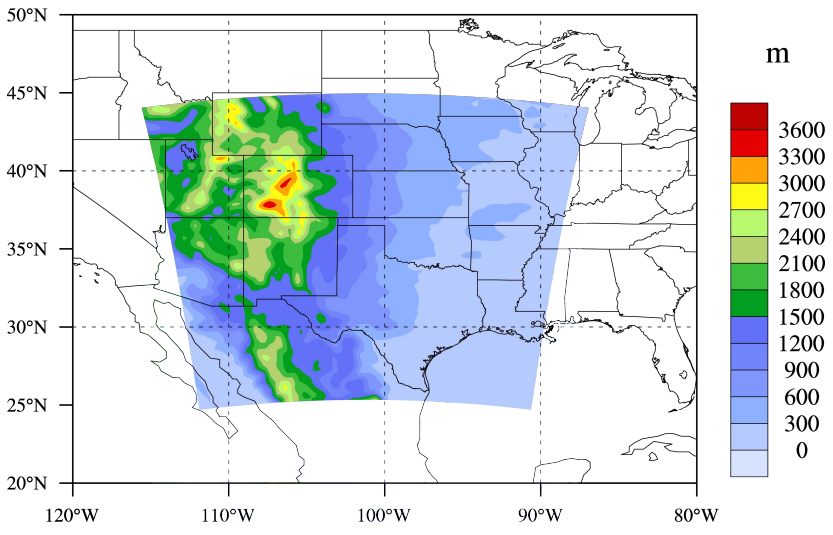

Fig. 2. WRF model domain (Southern Great Plain/SGP, $25-44^{\circ} \mathrm{N}$ and $112-90^{\circ} \mathrm{W}$ ) with grid spacing of $25 \mathrm{~km}$. Shades indicate the terrain (Unit: $\mathrm{m}$ ).

al., 2008) is used in this study. WRF is a fully compressible and non-hydrostatic model that uses a terrain-following hydrostatic-pressure vertical coordinate and an Arakawa Cgrid staggering spatial discretization for variables. The simulation domain is located within $25-44^{\circ} \mathrm{N}$ and $112-90^{\circ} \mathrm{W}$ over the SGP region (see Fig. 2), with horizontal grid spacing of $25 \mathrm{~km}$ and 36 sigma levels from the surface to $100 \mathrm{hPa}$. Wind, temperature, water vapor, pressure, and underlying surface variables used to generate initial and boundary conditions are derived from the North American Regional Reanalysis (NARR) data with 32-km horizontal resolution and 3-h time intervals.

To obtain a reasonable simulation result for precipitation over the SGP region before starting the optimization process, we compared two different radiation schemes, RRTMG (Rapid Radiative Transfer Model for GCMs, Barker et al., 2003; Pincus et al., 2003) vs. CAM (Community Atmosphere Model 3.0, Collins et al., 2004), and two different microphysics schemes, WSM6 (WRF Single-Moment 6-class, Hong and Lim, 2006) vs. Morrison 2-Moment (Morrison et al., 2005). Figure 3 shows the observed and simulated monthly mean precipitations for June 2007 with different radiation (RRTMG vs. CAM) and microphysical parameterization schemes (WSM6 vs. Morrison) while the standard KF CPS was used in both simulations. The results show that more than $70 \%$ of the rainfall is contributed by convective precipitation, indicating the importance of the CPS in simulating precipitation for the region in the summer. We find that the simulated precipitation is more sensitive to different radiation schemes than different microphysical schemes in this study. While the CAM radiation scheme tends to underestimate the amount of precipitation, the RRTMG seems to produce a more realistic magnitude and spatial pattern of precipitation. However the RRTMG scheme produces larger areas of precipitation than observed, especially over the northeast corner of the domain. Simulation result with the Morrison scheme is slightly better than with WSM6. Finally, RRTMG radiation and Morrison microphysics schemes, as well as the Mellor-Yamada-Janjic (MYJ, Janjic, 2002) PBL scheme and the Noah Land Surface Model (LSM) (Chen and Dudhia, 2001) were used in all simulations in this study.

We selected 1 May to 30 June 2007 for our simulations to focus on a wet month (June) with mostly convective-type precipitation. To isolate the influence of the convective parameterization, all model simulations, including those identifying the best configuration, were initialized every three days to minimize errors in the large-scale circulation that can also affect precipitation. Each simulation was initialized two days after the previous simulation. Discarding the first day as model spin-up, the results of the last two days of each simulation were concatenated to form a continuous time series for analysis. Unlike the atmospheric state, which was initialized every three days using the NARR data, the land surface state (soil moisture and temperature) was initialized based on simulation of the previous three days to produce better spun-up land surface conditions for realistic land-atmosphere interactions. As described in Sects. 3.4 and 3.5, the same experimental design was used to conduct simulations with different horizontal resolutions and over different regions.

\section{Results}

\subsection{Model response to five parameters}

The top panel of Fig. 4 shows the response of model performance (quantified as $E$ as introduced in Sect. 2.2) to five input parameters based on the 148 simulations through the MVFSA procedure. $E$ is equal to 137 in the simulation with default parameters in the KF CPS. Figure 4 shows that $E$ varies from 74 to 225 , with lower $E$ than 137 in the majority of experiments. We found that model response is more sensitive to the changes of $P_{\mathrm{d}}$ (downdraft flux rate related coefficient), $P_{\mathrm{e}}$ (entrainment rate related coefficient), and $P_{\mathrm{c}}$ (CAPE consumption time) than to the other two parameters. For example, the model bias $E$ significantly decreases with the increase of $P_{\mathrm{d}}$ or decrease of $P_{\mathrm{e}}$. The optimal values for $P_{\mathrm{d}}, P_{\mathrm{e}}$, and $P_{\mathrm{c}}$ that minimize $E$ are around $0.9,-0.9$, and $4600 \mathrm{~s}$, respectively. The optimal value for $P_{\mathrm{h}}$ and $P_{\mathrm{t}}$ are around $280 \mathrm{hPa}$ and $9 \mathrm{~m}^{2} \mathrm{~s}^{-2}$, both larger than the default values in the standard KF scheme for the starting height of downdraft above USL and the maximum TKE in the sub-cloud layer in this study. The responses of $E$ to variations in $P_{\mathrm{h}}$ and $P_{\mathrm{t}}$ are not as evident as those of the other three parameters.

Among the 148 valid simulations derived from the MVFSA procedure, there were 114 simulations with lower $E$ (better performance) than the standard KF scheme with default parameters. These 114 simulations are defined as "good" experiments. The middle panel of Fig. 4 shows the frequency distributions of the "good" experiments as a 

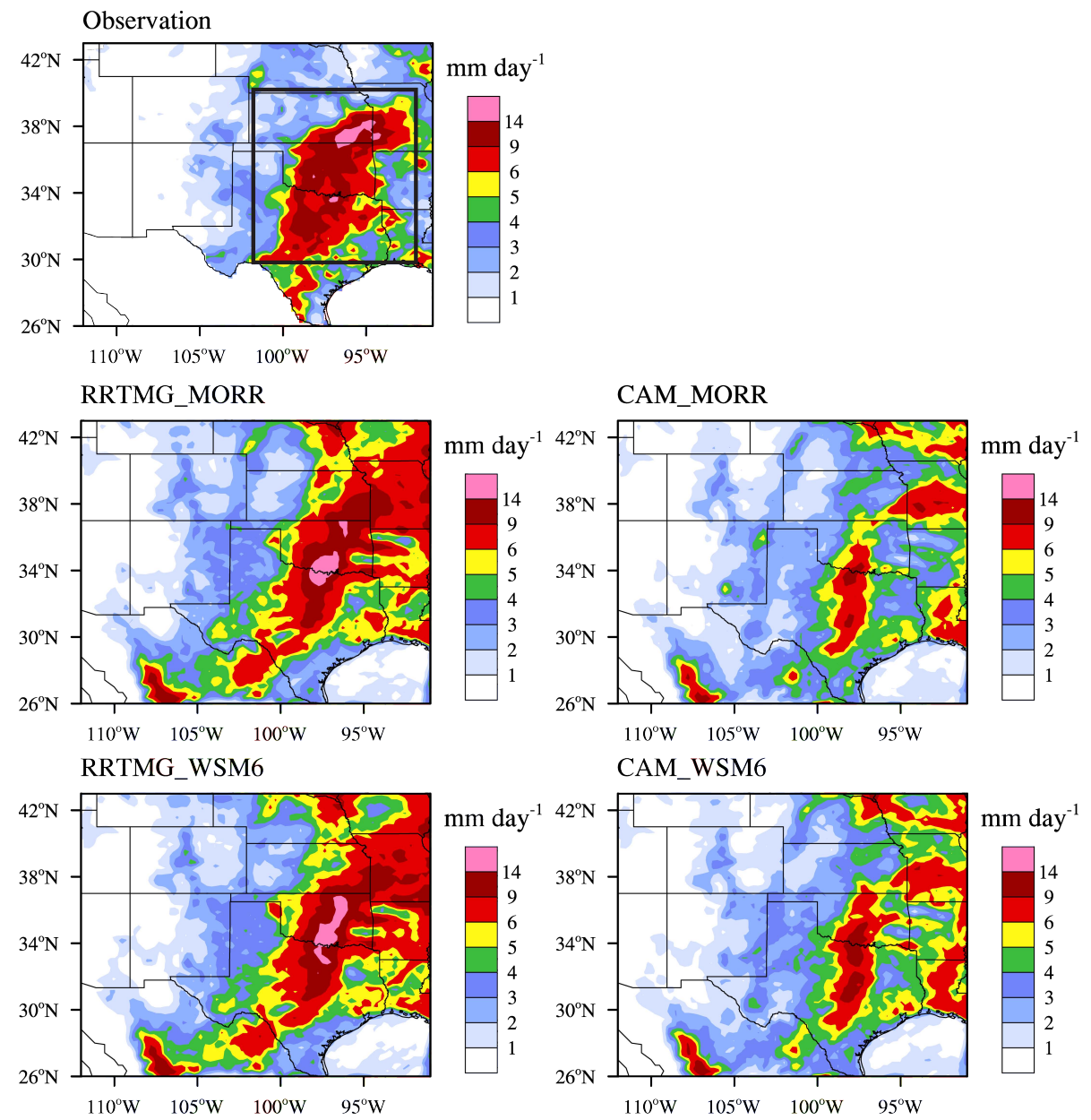

Fig. 3. Spatial distributions of observed and simulated $(25 \mathrm{~km})$ monthly mean precipitation over SGP for June 2007, with different radiation (RRTMG vs. CAM) and microphysics schemes (WSM6 vs. Morrison). Solid box highlighted in top panel shows the sub-region for later analysis.

function of each parameter value. We found that around $51 \%$ of the "good" experiments were produced by $P_{\mathrm{d}}$ from 0.6 to 1.0 , indicating that the ratio of downdraft to updraft mass fluxes shown in Eq. (1) is too small in the standard KF CPS. Approximately $60.5 \%$ of the "good" experiments were produced by $P_{\mathrm{e}}$ from -1.0 to -0.4 , indicating that the ratio of maximum possible entrainment rate to updraft mass fluxes shown in Eq. (2) is too large in the standard KF CPS. As $P_{\mathrm{h}}$, $P_{\mathrm{t}}$, and $P_{\mathrm{c}}$ are within the range from 230 to $320 \mathrm{hPa}, 9$ to $11 \mathrm{~m}^{2} \mathrm{~s}^{-2}$, and 3000 to $6000 \mathrm{~s}$, respectively, there are better chances to obtain relatively lower $E$ (better performance).

The marginal posterior probability distributions (PPD) for the five parameters derived from kernel density estimation are also shown in the bottom panel of Fig. 4. In statistics, kernel density estimation, a non-parametric way of estimating the PDF of a random variable, is a fundamental data smoothing problem where inferences about the population are made, based on a finite data. Different from the upper two panels of Fig. 4, the PPD was calculated using the proposed sample instead of the admitted samples to avoid the heavily biased admitted samples towards the mode. Similar to the middle panel of Fig. 4, large probabilities are located at around 0.8, $-0.7,320,9.5$ and 3200 , respectively for the five parameters of $P_{\mathrm{d}}, P_{\mathrm{e}}, P_{\mathrm{h}}, P_{\mathrm{t}}$ and $P_{\mathrm{c}}$.

Figure 5 shows the observed and simulated monthly mean precipitation for June 2007 with default and optimal parameters (see Table 2) in the simulations. Overall, the model with default parameters captures the spatial pattern but overpredicts the amount of precipitation, especially over the northeastern part of the domain. The simulation with $E$ based optimal parameters has significantly reduced the wet bias of the model, as $E$ decreases from 137 to 74 .

Skill scores $C$ describing the spatial pattern of precipitation (see Eq. 11) were calculated for all of the 148 experiments. The variations of $E$ and $C$ with perturbed parameters are closely correlated, with a correlation coefficient of 0.79 , implying that the spatial pattern of the precipitation would likely be improved if the magnitude of the model's bias was 

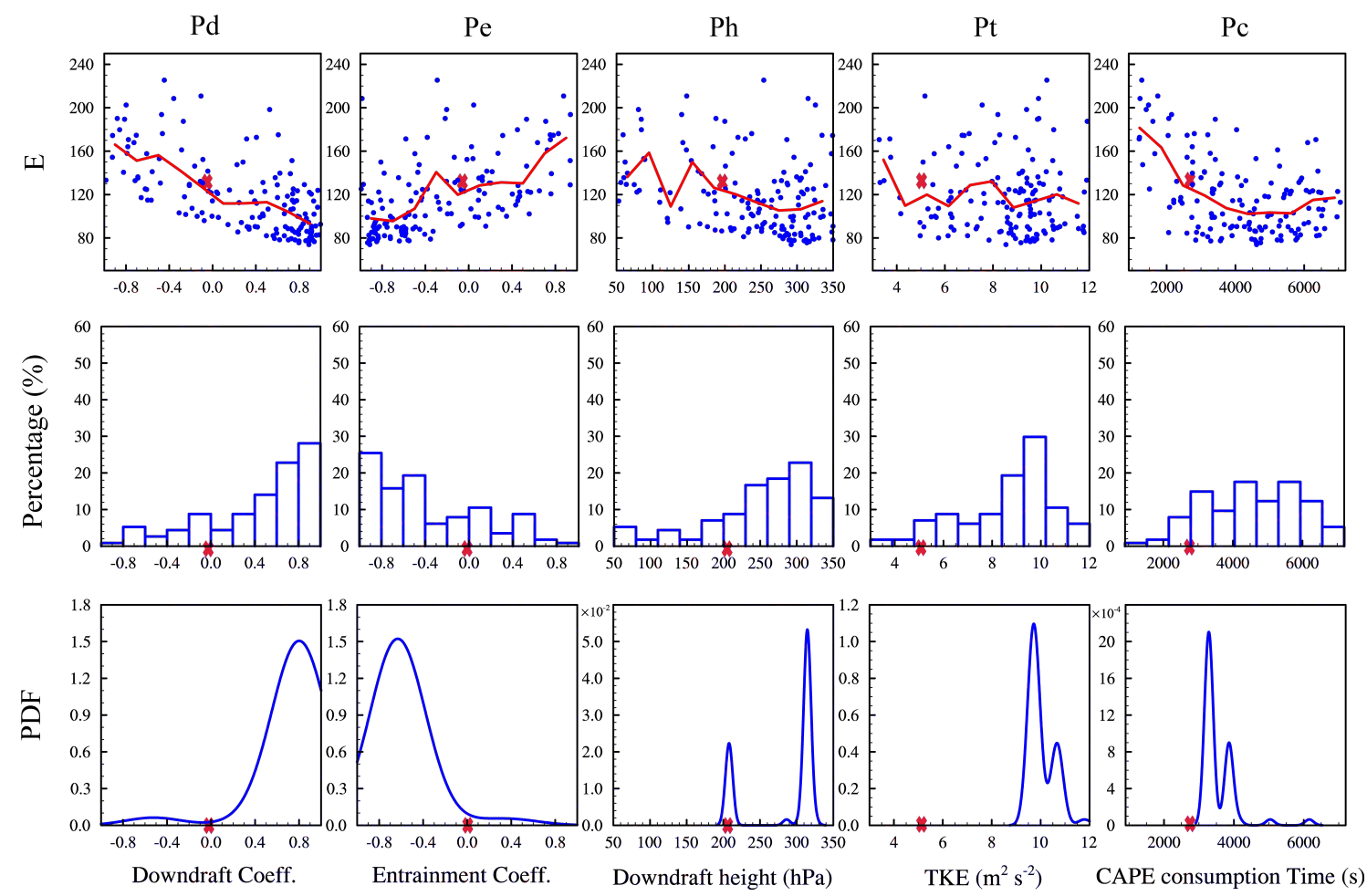

Fig. 4. (Top) The response of model performance (quantified as $E$ as introduced in Sect. 2.2) to five input parameters based on the 148 simulations $(25 \mathrm{~km})$ over SGP through the MVFSA procedure. Red curves represent an average of results at each bin. Default number of each parameter is marked as red crosses. (Middle) The frequency distributions of "good" experiments as a function of each parameter. "Good" experiments are defined as those with lower $E$ (better performance) than that using the standard KF scheme with default parameters. (Bottom) The marginal probability density functions (PDF) for the five input parameters derived by kernel density estimation.

reduced through the MVFSA process. Among the five input parameters, entrainment related parameter $P_{\mathrm{e}}$ has the most significant impact on $C$ (not shown).

$E C$ is calculated to represent the model performance in both magnitude and spatial pattern of precipitation. The bottom panel of Fig. 5 shows the simulations with optimal parameters based on $E$ and $E C$, respectively. The $E$ values for simulations with optimal $E$ and $E C$ are 74 and 79, respectively. The $C$ values are 0.34 and 0.36 , respectively, indicating that the spatial pattern in the simulation with optimal $E C$ is more similar to the observation than that of the default or with optimal $E$.

Figure 6 shows the observed and simulated frequencies of daily precipitation as a function of rain rate. Compared to the observation, the WRF with the standard KF CPS evidently overestimates the frequency of precipitation across all rain rates and the model wet bias becomes larger for heavy rain. By applying the optimal parameters based on $E$ (not shown) or $E C$, the model markedly reduced the overestimated occurrence frequency for rainy events larger than $3 \mathrm{~mm}$ day $^{-1}$. The improvement is more evident for the heavy precipitation with rain rate larger than $20 \mathrm{~mm} \mathrm{day}^{-1}$.
Table 2. The values of five identified parameters in the KF scheme, skill scores $E$ and $C$, used or obtained in the simulations with default or optimized (based on $E$ or $E C$, respectively) parameters.

\begin{tabular}{lrrrrrrr}
\hline & $P_{\mathrm{d}}$ & $P_{\mathrm{e}}$ & $P_{\mathrm{h}}$ & $P_{\mathrm{t}}$ & $P_{\mathrm{c}}$ & $E$ & $C$ \\
\hline Default & 0 & 0 & 150 & 5 & 2700 & 137 & 0.3 \\
Optimal $E$ & 0.89 & -0.91 & 292 & 8.54 & 4615 & 74 & 0.34 \\
Optimal $E C$ & 0.57 & -0.72 & 321 & 8.9 & 3597 & 79 & 0.36 \\
\hline
\end{tabular}

\subsection{Sensitivity of precipitation and correlation with other variables}

Figure 7 shows the responses of convective, explicit and total precipitation to each of the five parameters. As mentioned previously, total precipitation is contributed largely by the convective precipitation in this case study. The amount of explicit precipitation is around 0.2 to $1.5 \mathrm{~mm} \mathrm{day}^{-1}$, while convective precipitation varies between 3.8 and $9 \mathrm{~mm} \mathrm{day}^{-1}$. Because of the competition for moisture and physical interaction between the grid and sub-grid scale processes, the explicit precipitation is also affected by the CPS in the model 

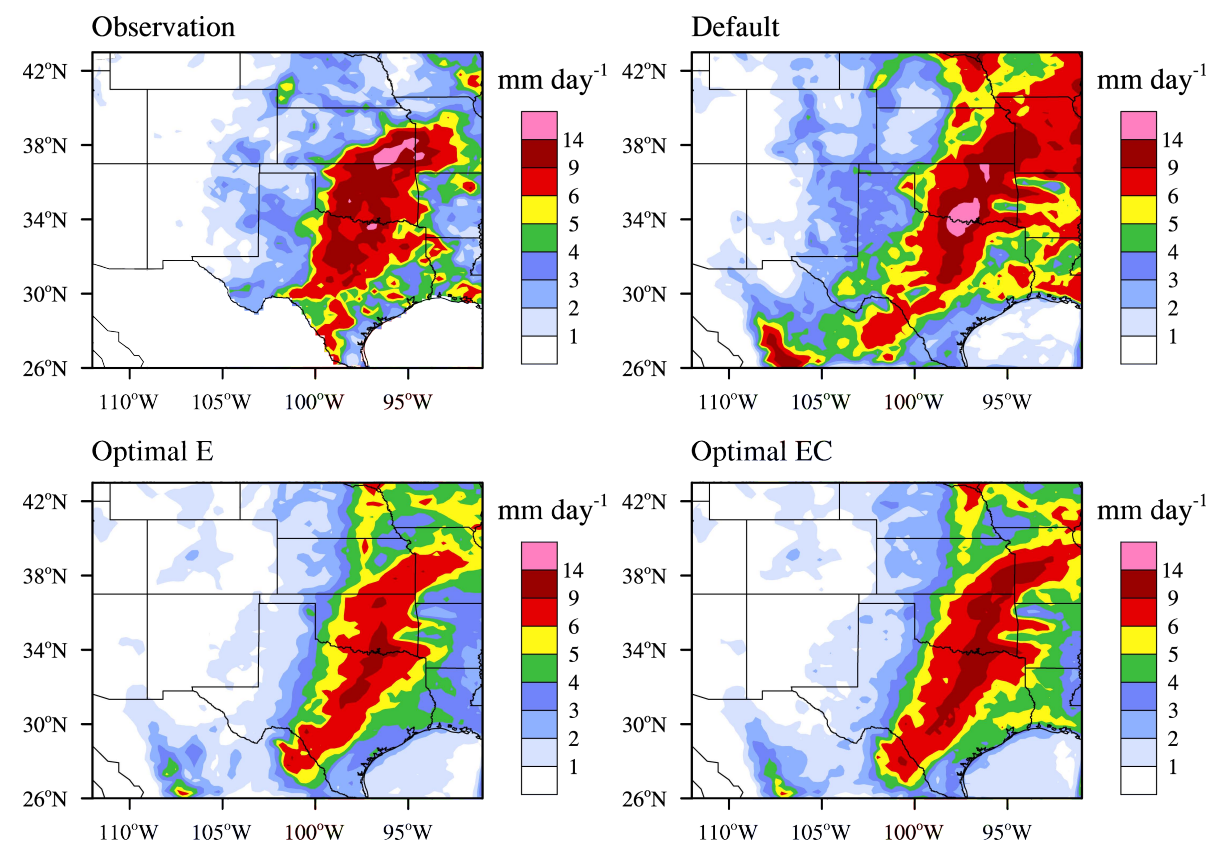

Fig. 5. Spatial distributions of observed and simulated $(25 \mathrm{~km})$ monthly mean precipitations over SGP for June 2007 , with default and optimized (based on $E$ or $E C$ ) parameters in the KF scheme.

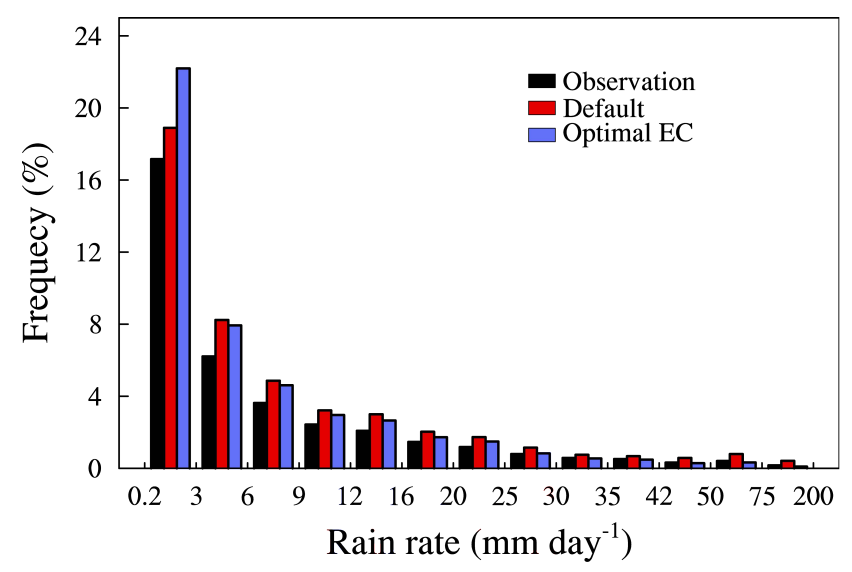

Fig. 6. The observed and simulated $(25 \mathrm{~km})$ frequency distributions of daily precipitation over SGP as a function of rain rates, with default and optimized (based on $E C$ ) parameters in the KF scheme. The result is derived from daily precipitation at all grids within the model domain as shown in Fig. 2 for June 2007.

(Kain, 2004), although the convective precipitation is more sensitive to the parameters.

From the middle panel of Fig. 7 we found that downdraft related parameter $P_{\mathrm{d}}$ and CAPE consumption time $P_{\mathrm{c}}$ have larger impact on the convective precipitation. With a larger ratio of downdraft to updraft flux (larger $P_{\mathrm{d}}$ ), more condensed water would be evaporated associated with a stronger downdraft process, resulting in less precipitation. The larger CAPE consumption time (larger $P_{\mathrm{c}}$ ) slows down the develop- ment and decreases the intensity of convection, thus reducing the convective precipitation. Stronger entrainment rate usually produces less convective precipitation because it dilutes the moist convective core, which tends to suppress the updraft (Kain and Fritsch, 1990; Zhang and McFarlane, 1995). The impact of TKE on convective precipitation is relatively small.

The change of explicit precipitation is often anti-correlated with the convective precipitation. When the convective precipitation is suppressed with the perturbed parameters, more moisture will be available in the atmosphere, favoring the formation of explicit precipitation calculated based on the microphysics scheme in the model. The top panel of Fig. 7 shows that the explicit precipitation is more sensitive to the parameters related to entrainment and CAPE consumption time than the other three parameters. Since total precipitation is mainly contributed by the convective precipitation, the responses of total precipitation to the five parameters are consistent with that of convective precipitation.

Figures 8 and 9 demonstrate how the changes of two parameters, $P_{\mathrm{d}}$ and $P_{\mathrm{e}}$, physically affect the convective process and other subsequent meteorological variables such as air temperature and humidity, cloud, and surface heat flux. In Fig. 8 we see clear response of the low-level cloud, water vapor, temperature and surface energy flux to the downdraftrelated parameter $P_{\mathrm{d}}$. While the downdraft flux became stronger with the increase of $P_{\mathrm{d}}$, it enhanced the evaporation of condensate, increasing the humidity and decreasing the temperature in the lower troposphere (900-800 hPa), which favors the formation of a low cloud. Consequently, increased 

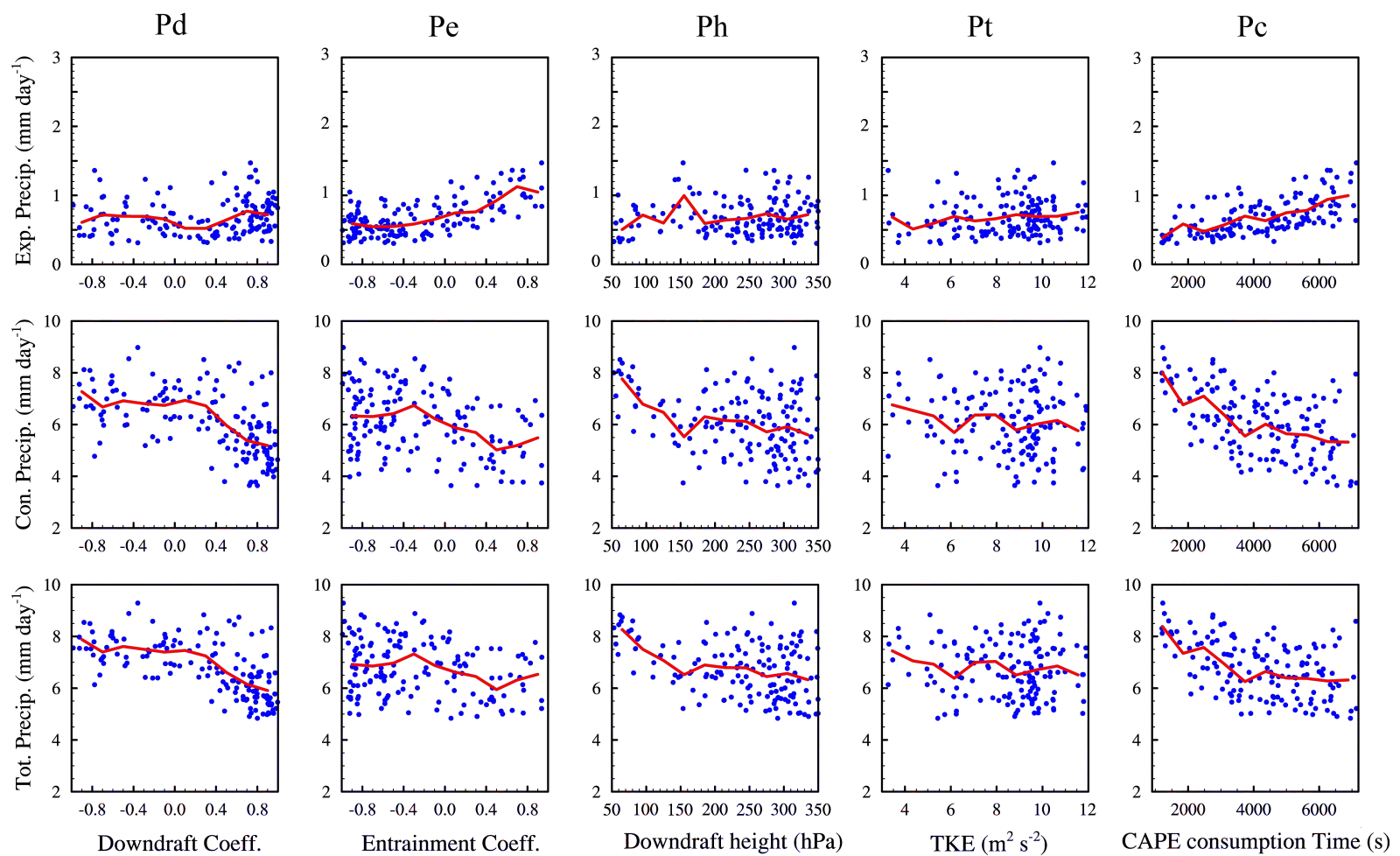

Fig. 7. The response of simulated explicit (top), convective (middle) and total (bottom) precipitation averaged over the sub-domain shown in Fig. 3 to the five parameters in the KF scheme. The meaning of red curves is same as in Fig. 4.

clouds reflect larger amounts of solar radiation back into space and reduce the solar radiation flux at the surface. Decreased surface shortwave radiation, together with decreased precipitation, suppressed the evaporation and reduced the latent heat flux (LH) at the surface. Meanwhile, the soil moisture also showed a decreasing trend with $P_{\mathrm{d}}$ partly due to the decreased precipitation. Different from the low troposphere, the PBL (1000-900 hPa) air moisture is less affected by the increasing downdraft flux because the PBL moisture is more influenced by the surface evapotranspiration. Increasing of $\mathrm{SH}$ is contributed by both cooling of PBL and decreasing of surface $\mathrm{LH}$ release.

The ratio of entrainment to updraft flux $\left(P_{\mathrm{e}}\right)$ also showed a remarkable impact on the convection process and weather system (see Fig. 9). With a larger entrainment rate, efficient mixing can suppress the development of updraft and increase the environmental air humidity at the middle $(800-600 \mathrm{hPa})$ atmosphere, so that deep convection is weakened and the cloud top height decreases (i.e. outgoing longwave radiation increases). In the lower atmosphere, the weaker condensate or evaporation that results from weaker updraft can increase temperature and produce fewer clouds. Consequently, the downward surface solar radiation and skin temperature significantly increase. Since the skin temperature and low-level air temperature increase consistently, a clear trend of sensible heat flux (SH) was not seen with the change of entrainment rate. LH increases primarily due to the increased downward solar radiation at the surface.

The impact of the downdraft starting height $P_{\mathrm{h}}$ on the convection process is similar to that of the downdraft rate (not shown). Downdraft flux initiating at a higher level can produce a tall and narrow downdraft, which has effects similar to a larger downdraft rate.

The relative sensitivities of the response of the meteorological variables to the five CPS parameters are shown in Fig. 10. The sensitivity ranking is calculated based on the correlation coefficients between output variables (y-axis) and input CPS parameters (x-axis) from 148 simulations, representing the variability of output variables against the perturbed input parameters (e.g. the slope of the fitted curve shown in Figs. 7-9). Figure 10 shows that $P_{\mathrm{d}}$ and $P_{\mathrm{e}}$ have more impact on the output variables than the other three input parameters, while most of the output variables are least sensitive to $P_{\mathrm{t}}$, the maximum TKE in the sub-cloud layer. The impact of CAPE consumption time $\left(P_{\mathrm{c}}\right)$ on precipitation is significant as discussed in Sects. 3.1 and 3.2, because $P_{\mathrm{c}}$ efficiently controls the development of the convection. As shown in Fig. 10, cloud water content, PBL specific humidity, outgoing longwave radiation (OLR) and downward longwave radiation are very sensitive to $P_{\mathrm{c}}$.

A total of 148 simulations with perturbed parameter sets were completed in this study, providing an opportunity to 


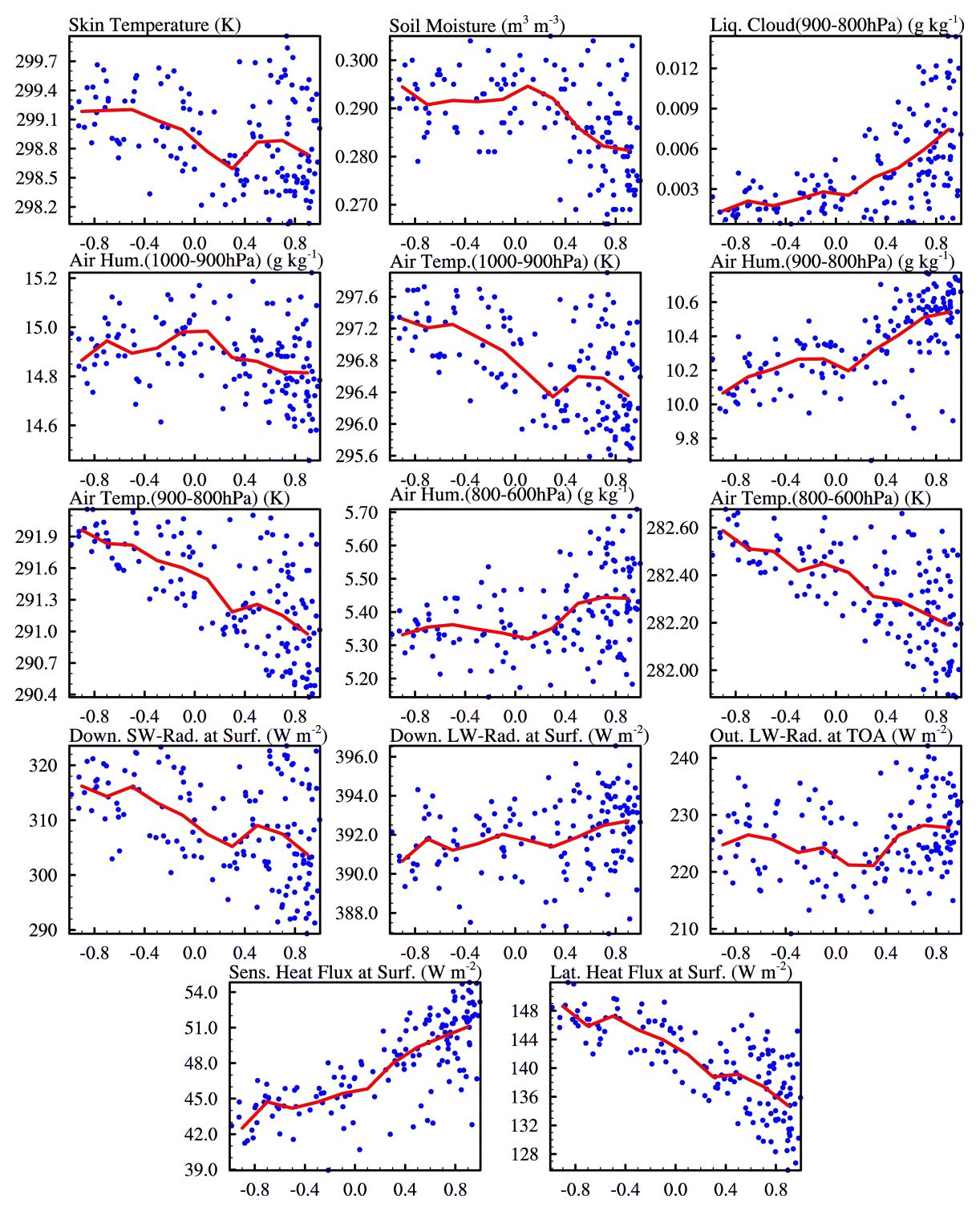

Fig. 8. The response of 14 model output variables (see Table 3 ) to the downdraft mass flux related parameter $P_{\mathrm{d}}$ based on the 148 simulations $(25 \mathrm{~km})$ over SGP.

investigate not only the response of various model variables to the CPS parameters but also the correlation and interaction among different model variables. As summarized in Table 3, strong positive correlations can be found between monthly mean convective precipitation and soil moisture, skin temperature and downward solar radiation flux, $\mathrm{LH}$ and air temperature, as well as LH and downward solar radiation flux. We found significant negative correlations between lower/mid-level air humidity and soil moisture, lowerlevel air humidity and convective precipitation, OLR and soil moisture, SH and air temperature, as well as LH and lowlayer cloud water content.

\subsection{Impact of optimization on temperature and wind speed}

Because only observed precipitation is used to constrain the MVFSA algorithm, the question arises as to how other simulated variables vary with the five CPS parameters when the model converges to the optimal results for precipitation. Table 4 shows the correlation coefficients of model skill scores between precipitation and 2-m temperature and $10-\mathrm{m}$ wind speed. The correlation coefficient is 0.31 between $E\left(T_{\text {mean }}\right)$ and $E_{(\mathrm{Prec})}$ and 0.76 between $E\left(T_{\text {mean }}\right)$ and $C_{(\mathrm{Prec})}$, indicating that the bias of model temperature is more correlated with spatial pattern than the bias of magnitude of simulated precipitation. The correlation coefficient between $E_{\text {(Wind) }}$ and 

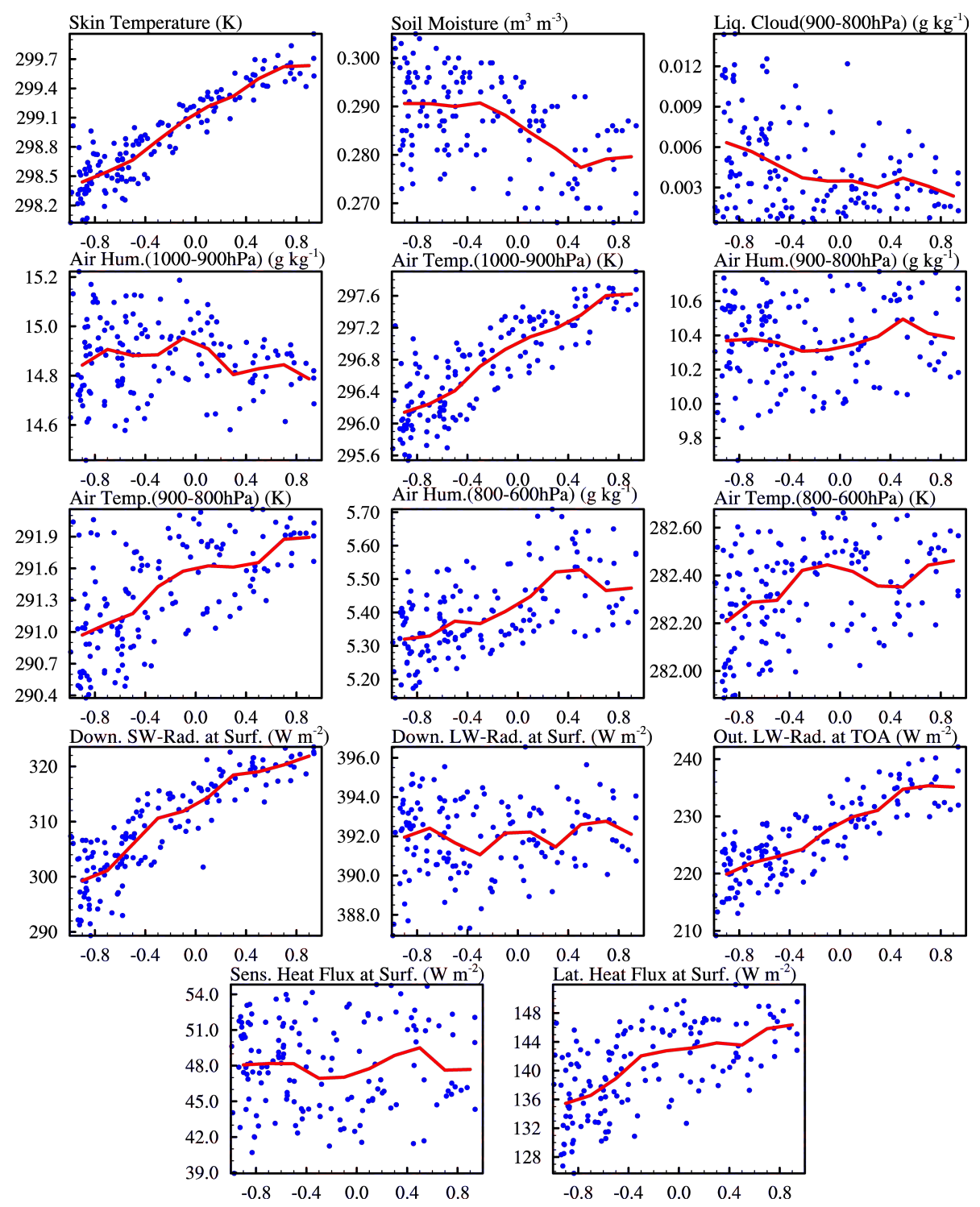

Fig. 9. Same as Fig. 8 except for the entrainment rate related parameter $P_{\mathrm{e}}$.

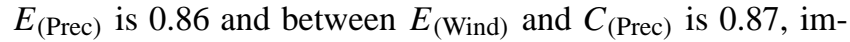
plying a consistent performance in simulating wind speed and precipitation (i.e. simulations with better precipitation are also more likely to have better wind speed).

Figure 11 shows the differences of model biases for temperatures and wind speed between the simulations with default and optimized parameters. Here, the value on each grid point is calculated as (|Optimal-Observation $|-|$ DefaultObservation|), so negative value represents a positive impact by using the optimized parameters. It can be seen that, except for the maximum temperature, all variables have reduced absolute biases with the optimized parameters than with the default parameters, especially over regions with strong precipitation, even though the optimal parameters are obtained only based on precipitation. The improvements for temperatures are more significant when using optimal parameters based on $E C$ than based on $E$ (not shown), which suggests that including precipitation pattern in the skill score metrics may be important in the optimization process.

\subsection{Dependence of optimized parameters on model grid spacing}

It is well known that the performance of CPS may vary with model resolution as current convective parameterizations generally exhibit scale dependence (Arakawa et al., 2011). Retuning of model parameters for high-resolution applications can be very time consuming and computationally intensive. In this study, the MVFSA procedure was performed based on WRF simulations at $25-\mathrm{km}$ grid spacing. To 
Table 3. Correlations among different model output variables in $148 \mathrm{WRF}$ simulations (25-km, SGP) with perturbed parameters in the KF scheme. The correlation coefficients are calculated based on the domain average as shown in Fig. 3. TS: skin temperature; SM: soil moisture; QC: cloud liquid water content at layers from 900 to $800 \mathrm{hPa}, Q(P)$ : air specific humidity for $1000-900 \mathrm{hPa}$; $T(P)$ : air temperature for $1000-900 \mathrm{hPa} ; Q(L)$ : air specific humidity for $900-800 \mathrm{hPa} ; T(L)$ : air temperature for $900-800 \mathrm{hPa}$; $Q(M)$ : air humidity for $800-600 \mathrm{hPa} ; T(M)$ : air temperature for $800-600 \mathrm{hPa}$; SWD: short-wave radiation at surface; LWD: downward long-wave radiation at surface; OLR: outward long-wave radiation at top of the atmosphere; SH: sensible heat flux at surface; LH: latent heat flux at surface; EP: explicit precipitation; $\mathrm{CP}$ : convective precipitation.

\begin{tabular}{|c|c|c|c|c|c|c|c|c|c|c|c|c|c|c|c|c|}
\hline TS & - & & & & & & & & & & & & & & & \\
\hline SM & -0.42 & - & & & & & & & & & & & & & & \\
\hline QC & -0.31 & -0.58 & - & & & & & & & & & & & & & \\
\hline$Q(P)$ & 0.23 & 0.44 & -0.26 & - & & & & & & & & & & & & \\
\hline$T(P)$ & 0.96 & -0.16 & -0.49 & 0.36 & - & & & & & & & & & & & \\
\hline$Q(L)$ & 0.02 & -0.86 & 0.75 & -0.48 & -0.23 & - & & & & & & & & & & \\
\hline$T(L)$ & 0.75 & 0.28 & -0.74 & 0.56 & 0.89 & -0.63 & - & & & & & & & & & \\
\hline$Q(M)$ & 0.38 & -0.83 & 0.19 & -0.64 & 0.16 & 0.67 & -0.2 & - & & & & & & & & \\
\hline$T(M)$ & 0.43 & 0.59 & -0.81 & 0.6 & 0.63 & -0.79 & 0.89 & -0.46 & - & & & & & & & \\
\hline SWD & 0.8 & -0.14 & -0.7 & -0.04 & 0.81 & -0.19 & 0.72 & 0.44 & 0.54 & - & & & & & & \\
\hline LWD & 0.29 & -0.52 & 0.65 & 0.39 & 0.16 & 0.49 & -0.07 & 0.02 & -0.26 & -0.32 & - & & & & & \\
\hline OLR & 0.76 & -0.86 & 0.2 & -0.21 & 0.56 & 0.58 & 0.18 & 0.75 & -0.11 & 0.52 & 0.46 & - & & & & \\
\hline SH & -0.18 & -0.75 & 0.6 & -0.69 & -0.44 & 0.85 & -0.73 & 0.77 & -0.82 & -0.18 & 0.15 & 0.44 & - & & & \\
\hline LH & 0.66 & 0.35 & -0.86 & 0.37 & 0.82 & -0.62 & 0.93 & -0.13 & 0.86 & 0.82 & -0.32 & 0.11 & -0.71 & - & & \\
\hline EP & 0.69 & -0.77 & 0.35 & -0.05 & 0.54 & 0.56 & 0.17 & 0.45 & -0.16 & 0.3 & 0.64 & 0.84 & 0.25 & 0.05 & - & \\
\hline \multirow[t]{2}{*}{$\mathrm{CP}$} & -0.29 & 0.97 & -0.71 & 0.37 & -0.04 & -0.91 & 0.39 & -0.71 & 0.65 & 0.04 & -0.64 & -0.79 & -0.76 & 0.48 & -0.76 & - \\
\hline & TS & SM & QC & $Q(P)$ & $T(P)$ & $Q(L)$ & $T(L)$ & $Q(M)$ & $T(M)$ & SWD & LWD & OLR & $\mathrm{SH}$ & LH & EP & CP \\
\hline
\end{tabular}

Table 4. Correlations of model performance between the precipitation and the mean/maximum/minimum 2-m temperature and 10-m wind speed. The correlation coefficients are calculated on the basis of skill scores for the precipitation (based on $E$ and $C$, respectively) and for the temperature and wind speed (based on $E$ ) of the 148 simulations $(25-\mathrm{km})$ over SGP.

\begin{tabular}{lrrrr}
\hline & $E\left(T_{\text {mean }}\right)$ & $E\left(T_{\max }\right)$ & $E\left(T_{\text {min }}\right)$ & $E_{(\text {Wind })}$ \\
\hline$E($ Prec $)$ & 0.31 & -0.18 & 0.51 & 0.86 \\
$C($ Prec $)$ & 0.76 & 0.17 & 0.78 & 0.87 \\
\hline
\end{tabular}

assess the transferability of model calibration across spatial scales, we completed two simulations with a higher resolution $(12-\mathrm{km})$ with default and optimal parameters obtained from the $25-\mathrm{km}$ simulations. Identical model configurations and domain size were used between the $25 \mathrm{~km}$ and $12 \mathrm{~km}$ resolution simulations.

Figure 12 shows the spatial distributions of observed and simulated precipitation with default and optimal parameters, respectively. We found that with default CPS parameters in the standard KF, the model can reasonably capture the spatial pattern of precipitation but significantly overestimates the maximum precipitation, especially over Oklahoma, the Kansas-Missouri border, and the Texas-Louisiana border. By using the optimal parameters obtained from the $25-\mathrm{km}$ simulations, both the magnitude and spatial pattern of precipitation are improved at $12-\mathrm{km}$ spatial resolution, with $E$ decreasing from 148 to 89 and $C$ increasing from 0.3 to

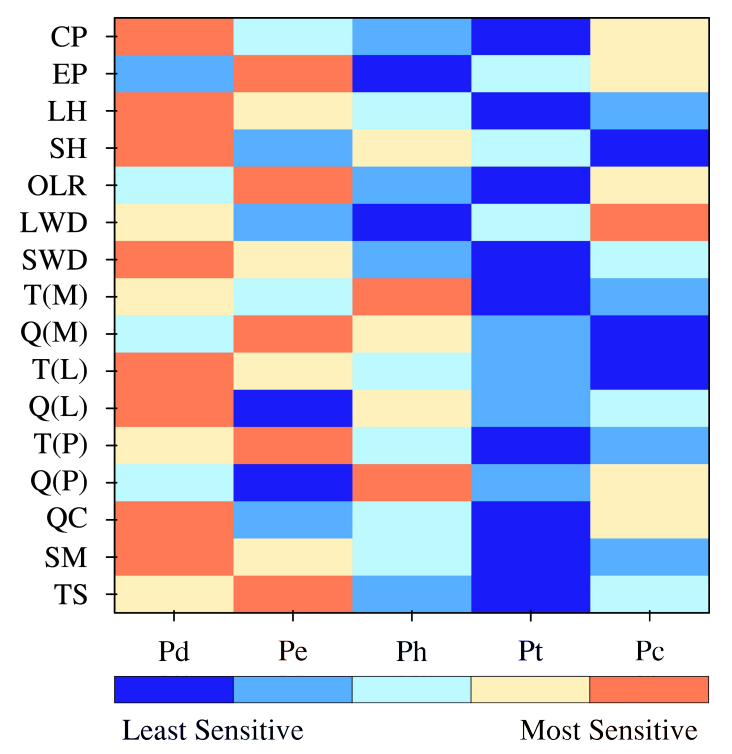

Fig. 10. Relative sensitivities of the response of the 16 meteorological variables (see Table 3 ) to the five CPS parameters (see Table 1$)$ based on the 148 simulations $(25 \mathrm{~km})$ over SGP. The sensitivity ranking is calculated based on the correlation coefficients between output variables (y-axis) and input CPS parameters (x-axis) from 148 simulations.

0.37. These results suggest that quantitative optimization may yield more robust model parameters that can improve precipitation simulation across a range of spatial scales. 
Tmean_2m

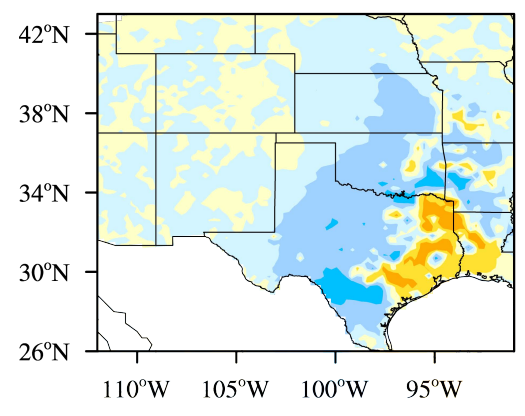

Tmin_2m

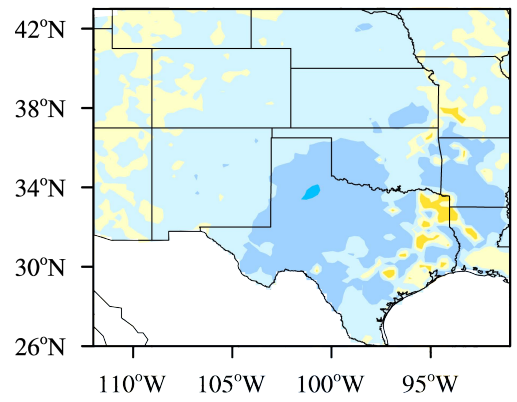

Tmax $\_2 m$
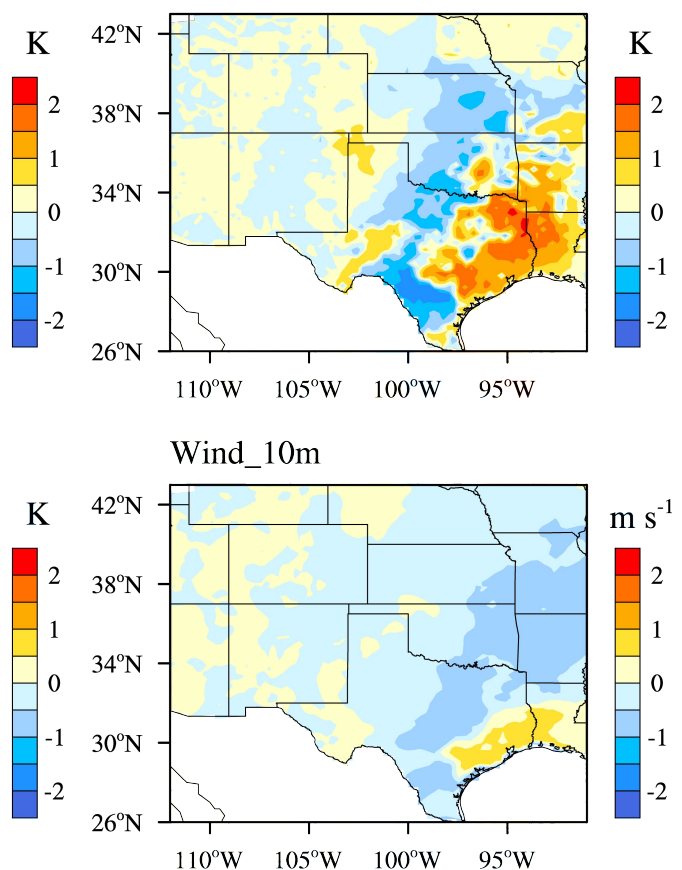

\section{Wind_10m}

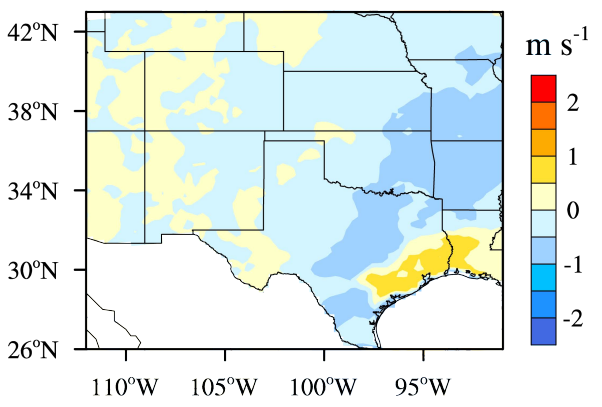

Fig. 11. The spatial distributions of the differences of model biases for temperatures and wind speed between the simulations (25-km) with the default and optimized parameters. Here, the value on each grid point is calculated as (|Optimal-Observation $|-|$ Default-Observation $\mid)$, so negative value represents a positive impact by using optimized parameters.

\subsection{Dependence of optimized parameters on climate regime}

In the previous sections, optimization was performed for a regional model applied to a specific region (i.e. the SGP). However, the physical process and mechanism of convection and precipitation may differ in different climatic regimes (Knupp and Cotton, 1985; Grant, 2001; Kain et al., 2001). For example, Liang et al. (2004) showed that simulations of summer rainfall in the U.S. could be very sensitive to the CPS used because relative influence of large-scale tropospheric forcing and boundary layer forcing in triggering convection may vary in different CPSs. A critical question is how parameters optimized based on application in one regimes transfer to a different climate regime.

We completed two additional simulations over the North America Monsoon (NAM) region $\left(23-40^{\circ} \mathrm{N}, 121-100^{\circ} \mathrm{W}\right)$ using $25-\mathrm{km}$ grid spacing on both simulations with default and optimal parameters, respectively. The NAM represents a distinctly different climate regime compared to the SGP in the central US (Berbery, 2001; Englehart and Douglas, 2006). For example, convection in the semi-arid NAM region is associated with strong surface heating, with a dominant late afternoon precipitation maxima related to the buildup of CAPE during the day. In the central US, on the other hand, precipitation maxima shows a distinct nocturnal maxima associated with increased nighttime moisture brought in by the
Great Plain Low-Level Jet. Figure 13 shows the spatial distributions of observed and simulated precipitation with default and optimal parameters over the NAM region for July 1991. The model with default CPS parameters overestimates the maximum precipitation over coastal areas in northern Mexico. Precipitation over eastern New Mexico and the southern Colorado-Kansas border is also largely overestimated. As optimal parameters are applied, the precipitation over those regions is obviously improved, with $E$ decreasing from 110 to 65 and $C$ increasing from 0.26 to 0.31 .

Similar to Fig. 6, Fig. 14 shows the observed and simulated frequencies of daily precipitation as a function of rain rate over the NAM region for July 1991. Compared with the observation, the WRF with default CPS parameters in the standard KF evidently overestimates the frequency of precipitation across all rain rates. By applying the optimal parameters based on $E C$ over SGP, the model markedly reduces the overestimated occurrence frequency for all rainy events except for light rain smaller than $3 \mathrm{~mm} \mathrm{day}^{-1}$ over the NAM region. The improvement is particularly evident for the moderate and heavy precipitation rain rates of more than $12 \mathrm{~mm} \mathrm{day}^{-1}$. These results suggest the optimal parameters determined based on one regime are transferable and lead to obvious improvements in model performance in a different regime. 

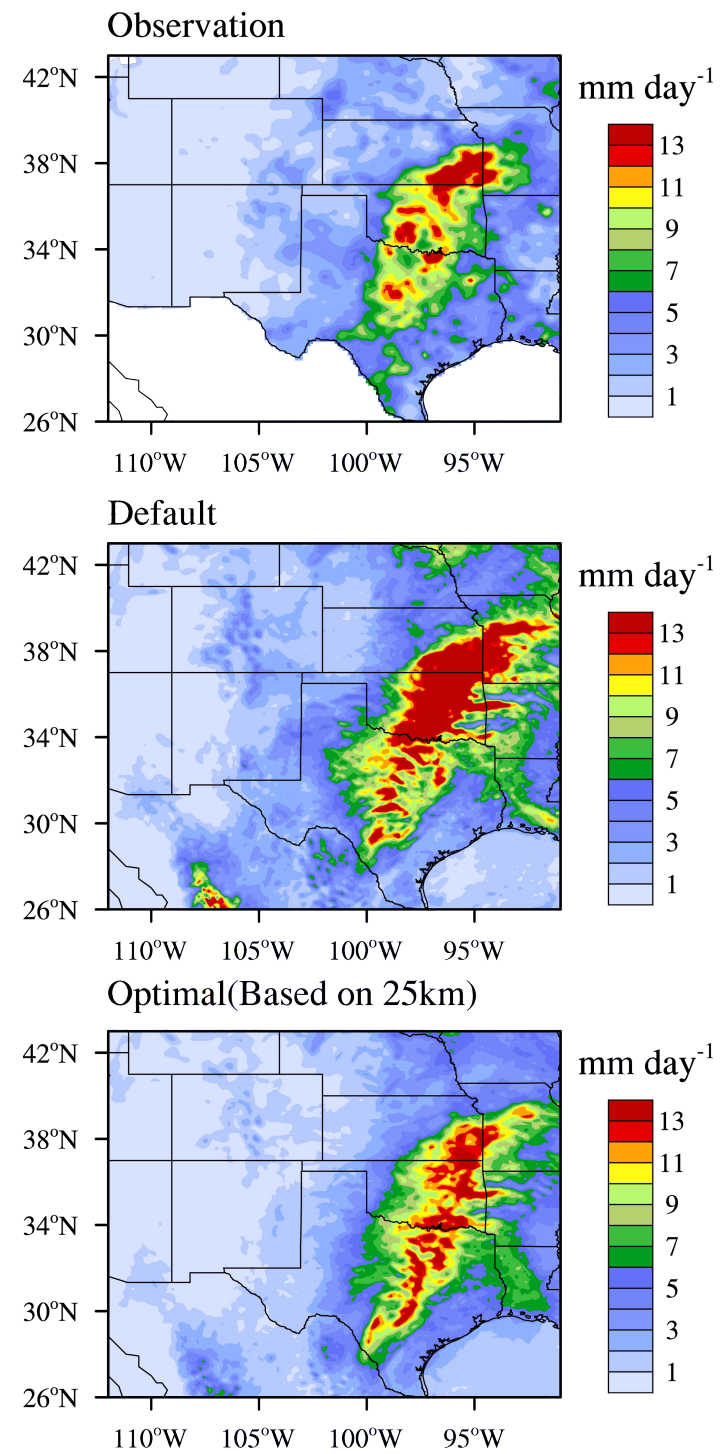

Fig. 12. The spatial distributions of observed and WRF simulated (with $12-\mathrm{km}$ spatial resolution) monthly mean precipitations over SGP for June 2007, with default and optimal parameters based on 25-km simulation.

\section{Summary and discussion}

Currently, Uncertainty Quantification (UQ) and parameter tuning in climate study are mostly applied in Global Climate Models (GCM). This may compromise the tuning by equal weighting of the state fidelity globally, even though the processes being tuned may only be relevant for particular regimes. The tuning process of parameters is often performed subjectively, although some studies have also applied an optimization procedure to minimize the difference between model fields and observations. While the latter approach may provide more plausible values for a set of tunable parameters to approximate the observed global climate
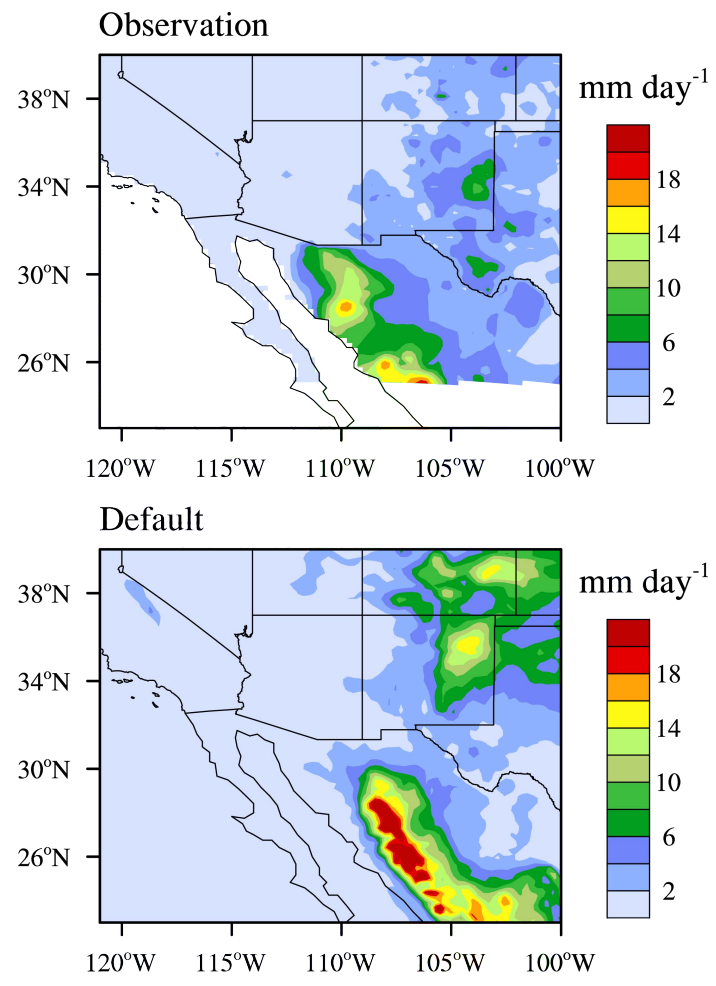

Optimal (Based on sgp)

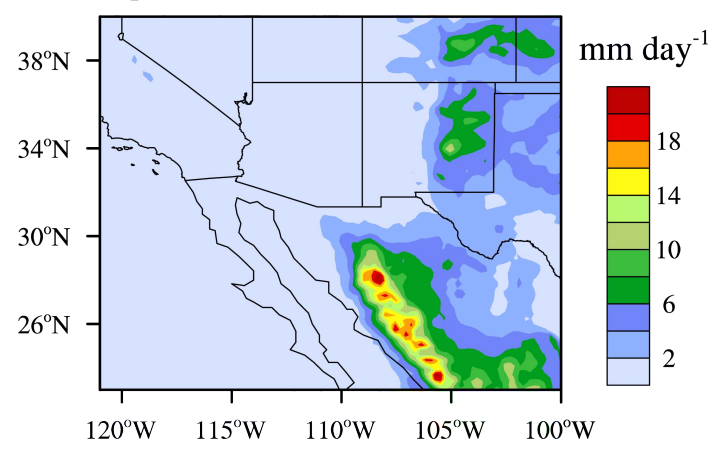

Fig. 13. The spatial distributions of observed and simulated $(25-\mathrm{km})$ monthly mean precipitation with default and optimal parameters obtained at the SGP, respectively, over the North America Monsoon (NAM) region for July of 1991.

or large-scale features, it is possible that the latter may be achieved by forcing the system to an unrealistic physical state or improper balance of budgets through compensating errors over different regions in the globe. In this study, regional climate model, the Weather Research and Forecasting (WRF) model, was used to provide a more flexible framework to investigate a number of issues related UQ and parameter tuning. The WRF model was constrained by reanalysis data over the Southern Great Plains (SGP), where abundant observational data from various sources were available for calibration of input parameters and validation of model results. Focusing on five key input parameters in the new Kain-Fritsch (KF) convective parameterization scheme (CPS) used in the 


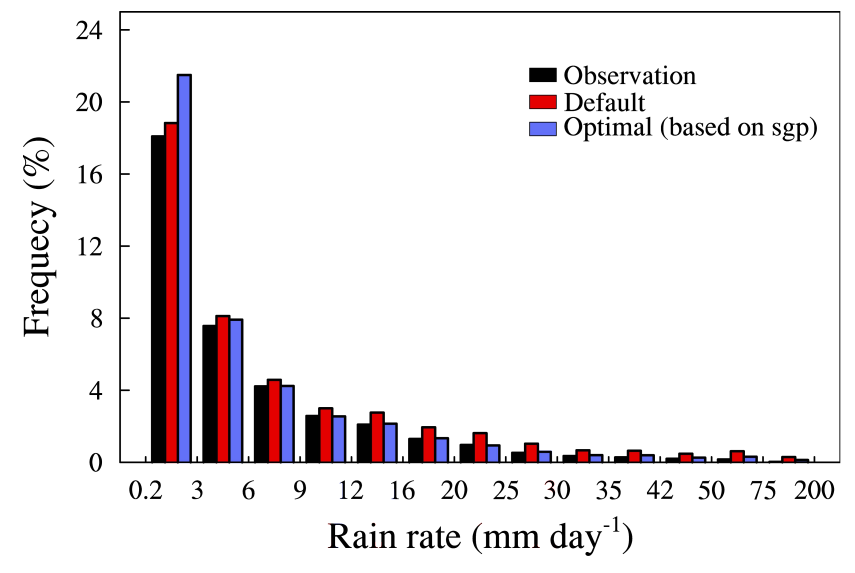

Fig. 14. The observed and simulated $(25-\mathrm{km})$ frequency distributions of daily precipitation over NAM for July 1991 as a function of rain rates, with default and optimized (based on EC in SGP) parameters in the KF scheme.

WRF model as an example, our goal was to explore the utility of high-resolution observations for improving simulations of regional patterns and evaluate the transferability of UQ and parameter tuning across physical processes, spatial scales, and climatic regimes, which have important implications to UQ and parameter tuning in global models. The five parameters identified in the KF scheme are related to downdraft flux rate and starting height, environment flux rate, turbulent kinetic energy (TKE) in the sub-cloud layer, and the consumption time of Convective Available Potential Energy (CAPE), respectively. A stochastic sampling algorithm, Multiple Very Fast Simulated Annealing (MVFSA), was employed to efficiently sample the input parameters in the KF scheme based on a skill score so that the algorithm progressively moves toward regions of the parameter space that minimize model errors.

The WRF simulation period was from 1 May to 30 June 2007 , and was reinitialized every three days, with $25-\mathrm{km}$ grid spacing over the SGP. The results show the model bias for precipitation can be significantly reduced by using five optimal parameters identified by the MVFSA algorithm, especially for heavy precipitation with rain rates over $20 \mathrm{~mm} \mathrm{day}^{-1}$. The model response to precipitation and other model variables was more sensitive to the changes of downdraft- and entrainment-related parameters and consumption time of CAPE than to the other two parameters. Utilizing high-resolution observations, the simulated spatial pattern of precipitation was improved when the magnitude of model biases was reduced through the MVFSA process. The simulated convective precipitation decreases as the ratio of downdraft to updraft flux increases. Larger CAPE consumption time results in less convective but more stratiform precipitation.

The simulation using optimal parameters obtained by constraining precipitation alone generated positive impacts on other output variables, such as temperature and wind. By using the optimal parameters obtained at $25-\mathrm{km}$ simulation, both the magnitude and spatial pattern of precipitation are also improved at $12-\mathrm{km}$ spatial resolution. When moving the model domain to the North American Monsoon region, the optimal parameters identified from the SGP region also improved the simulation of precipitation, especially those with moderate and heavy precipitation with rain rates of more than $12 \mathrm{~mm} \mathrm{day}^{-1}$. These results suggest that benefits of optimal parameters determined through vigorous mathematical procedures such as the MVFSA process are transferable across processes, spatial scales, and climatic regimes to some extent. While our findings are preliminary, they motivate future studies to further assess the strategies for UQ and parameter optimization at both global and regional scales.

A number of limitations should be taken into account in evaluating the results of this study and in planning future studies. The primary limitation is that we assessed the model performance and tunable parameters based on differences in observed and modeled daily precipitation. Although most of the total rainfall was contributed by convective precipitation generated from the CPS in our case, the tuning process may still produce parameter settings that approximate the total observed rainfall, although the balance of different physical processes to achieve the total precipitation amount is not directly constrained. It is possible that the optimal parameters may only work well with the particular cloud microphysical scheme selected for this study. Furthermore, it may be more appropriate and beneficial to calibrate model parameters by constraining the behavior of physical processes (i.e. the turbulence, shallow and deep convection process in this study) rather than precipitation, which is a product of many interacting processes with large numbers of sources and sinks.

Second, the two regions (SGP and NAM) selected in this study are both convection-dominated climate regimes and precipitation are overestimated using the default model parameters in both regions. It is not clear whether optimization performed for one region is also transferable to another region if model biases with the default parameters are of opposite sign in the two regions. The issue of transferability of the benefits of optimization across different climate regimes and different spatial resolutions is being investigated further along with optimization of other physical parameterization schemes, which will be reported in a follow on paper. Third, how to define the skill metrics for evaluating model performance can be improved. In future studies, we would construct an auto-tuning procedure to minimize the bias in not only precipitation but also process-level variables, such as eddy diffusivities, PBL height, shallow convective mass fluxes, radiative heating rates, and so forth. In addition, future studies should also explore the use of spatial correlation coefficient, in addition to mean bias, in the skill score metrics for the optimization process, as this study already showed that spatial correlation provides useful information for model evaluation. In addition, uncertainties in the observations are 
not considered in this study, which may impact the shape of the posterior PDF of the input parameters and the model outputs including extreme events (Jackson et al., 2003). Fourth, different optimization approaches may affect the results and conclusions, but this issue has not been investigated in this study. We are currently comparing the MVFSA method and another sampling algorithm, the Annealing Evolutionary Stochastic Approximation Monte Carlo (AESAMC) (Liang, 2010), to investigate the convergence efficiency and the impact on the results.

Finally, the simulations conducted in this study were initialized every three days by reanalysis data. This weather forecast mode of simulation minimizes potential discrepancy between observed and simulated large scale circulation so model biases can be more directly related to the convective parameterization and its parameters. In future studies, we will compare model response and performance based on optimization process in free running simulations (i.e. climate simulation mode) strictly constrained (driven) by large-scale observations/reanalysis. Establishing the transferability of optimized parameters between weather and climate simulations would provide indirect evidence further supporting the seamless prediction strategy (Hurrell et al., 2009) and the transpose method of evaluating and diagnosing climate model biases through hindcast weather forecast simulations (e.g. Boyle et al., 2005).

Acknowledgements. The authors acknowledge Jack Kain of NOAA National Severe Storm Laboratory and Samson Hagos and Zhangshuan Hou of PNNL for their helpful comments, and Yichen Cheng for the PDF analysis. This work is supported by the US Department of Energy (DOE) Office of Science's Advanced Scientific Computing Research Applied Mathematics program. A portion of the computations were performed using resources of the National Center for Computational Sciences (NCCS) at Oak Ridge National Laboratory (ORNL), Environmental Molecular Sciences Laboratory (EMSL) at Pacific Northwest National Laboratory (PNNL), as well as the National Energy Research Scientific Computing Center (NERSC) at Lawrence Berkeley National Laboratory (LBNL). PNNL is operated by Battelle for the DOE under Contract DE-AC06-76RLO 1830.

Edited by: Q. Fu

\section{References}

Allen, M. R., Stott, P. A., Mitchell, J. F. B., Schnur, R., and Delworth, T. L.: Quantifying the uncertainty in forecasts of anthropogenic climate change, Nature, 407, 617-620, 2000.

Arakawa, A., Jung, J.-H., and Wu, C.-M.: Toward unification of the multiscale modeling of the atmosphere, Atmos. Chem. Phys., 11, 3731-3742, doi:10.5194/acp-11-3731-2011, 2011.

Barker, H. W., Pincus, R., and Morcrette, J.-J.: The Monte-Carlo Independent Column Approximation: Application within largescale models. Proceedings of the GCSS/ARM Workshop on the Representation of Cloud Systems in Large-Scale Models, May 2002, Kananaskis, Alberta, Canada, 10 pp., 2003.
Bechtold, P., Bazile, E., Guichard, F., Mascart, P., and Richard, E.: A mass-flux convection scheme for regional and global models, Q. J. Roy. Meteorol. Soc., 127, 869-886, 2001.

Berbery, E. H.: Mesoscale moisture analysis of the North American monsoon, J. Climate, 14, 121-137, 2001.

Boyle, J. S., Williamson, D., Cederwall, R., Fiorino, M., Hnilo, J., Olson, J., Phillips, T., Potter, G., and Xie, S.: Diagnosis of Community Atmospheric Model 2 (CAM2) in numerical weather forecast configuration at Atmospheric Radiation Measurement sites, J. Geophys. Res., 110, D15S15, doi:10.1029/2004JD005042, 2005.

Chen, F. and Dudhia, J.: Coupling an advanced land surfacehydrology model with the Penn State-NCAR MM5 modeling system. Part I: Model implementation and sensitivity, Mon. Weather Rev., 129, 569-585, 2001.

Cheng, M. D.: Effects of Downdrafts and Mesoscale Convective Organization on the Heat and Moisture Budgets of Tropical Cloud Clusters. Part II: Effects of Convective-Scale Downdrafts, J. Atmos. Sci., 46, 1540-1564, 1989.

Collins, W. D., Rasch, P. J., Boville, B. A., Hack, J. J., McCaa, J. R., Williamson, D. L., Kiehl, J. T., and Briegleb, B.: Description of the NCAR Community Atmosphere Model (CAM 3.0), NCAR Technical Note, NCAR/TN-464+STR, 226 pp., 2004.

Collins, M., Booth, B. B. B., Bhaskaran, B., Harris, G. R., Murphy, J. M., Sexton, D. M. H., and Webb, M. J.: Climate model errors, feedbacks and forcings: a comparison of perturbed physics and multi-model ensembles, Climate Dyn., 36, 17371766, doi:10.1007/s00382-010-0808-0, 2011.

Colman, R.: A comparison of climate feedbacks in general circulation models, Climate Dyn., 20, 865-873, doi:10.1007/s00382003-0310-z, 2003.

Covey, C., Brandon, S., Bremer, P.-T., Domyancic, D., Garaizar, X., Johannesson, G., Klein, R., Klein, S. A., Lucas, D. D., Tannahill, J., and Zhang, Y.: Quantifying the uncertainties of climate prediction, B. Am. Meteorol. Soc., submitted, 2011.

Emanuel, K. A. and Zivkovic-Rothman, M.: Development and evaluation of a convective scheme for use in climate models, J. Atmos. Sci., 56, 1766-1782, 1999.

Englehart, P. J. and Douglas, A. V.: Defining intraseasonal rainfall variability within the North American monsoon, J. Climate, 19, 4243-4253, 2006.

Ferrier, B. S., Simpson, J., and Tao, W. K.: Factors responsible for precipitation efficiencies in midlatitude and tropical squall simulations, Mon. Weather Rev., 124, 2100-2125, 1996.

Gilmore, M. S., Straka, J. M., and Rasmussen, E. N.: Precipitation uncertainty due to variations in precipitation particle parameters within a simple microphysics scheme, Mon. Weather Rev., 132, 2610-2627, 2004.

Giorgi, F. and Mearns, L. O.: Calculation of average, uncertainty range, and reliability of regional climate changes from AOGCM simulations via the "reliability ensemble averaging" (REA) method, J. Climate, 15, 1141-1158, 2002.

Grant, A. L. M.: Cloud-base fluxes in the cumulus-capped boundary layer, Q. J. Roy. Meteorol. Soc., 127, 407-421, 2001.

Gregory, D., Morcrette, J. J., Jakob, C., Beljaars, A. C. M., and Stockdale, T.: Revision of convection, radiation and cloud schemes in the ECMWF Integrated Forecasting System, Q. J. Roy. Meteorol. Soc., 126, 1685-1710, 2000.

Grell, G. A. and Devenyi, D.: A generalized approach 
to parameterizing convection combining ensemble and data assimilation techniques, Geophys. Res. Lett., 29, 1693, doi:10.1029/2002GL015311, 2002.

Haario, H., Saksman, E., and Tamminen, J.: An adaptive Metropolis algorithm, Bernoulli, 7, 223-242, 2001.

Hacker, J. P., Ha, S.-Y., Snyder, C., Berner, J., Eckel, F. A., Pocernich, M., Schramm, J., and Wang, X.: The U.S. Air Force Weather Agency's mesoscale ensemble: Scientific description and performance results, Tellus, 63, 625-641, doi:10.1111/j.1600870.2010.00497, 2011.

Hawkins, E. and Sutton, R.: The potential to narrow uncertainty in regional climate predictions, B. Am. Meteorol. Soc., 90, 10951107, doi:10.1175/2009BAMS2607.1, 2009.

Hong, S.-Y. and Lim, J.-O. J.: The WRF Single-Moment 6-Class Microphysics Scheme (WSM6), J. Korean Meteor. Soc., 42, 129-151, 2006.

Hurrell, J., Meehl, G., Bader, D., Delworth, T., Kirtman, B., and Wielicki, B.: A unified modeling approach to climate system prediction, B. Am. Meteorol. Soc., 90, 1819-1832, doi:10.1175/2009BAMS2752.1, 2009.

Ingber, L.: Very Fast Simulated Re-Annealing, Math. Comput. Model., 12, 967-973, 1989.

Intergovernmental Panel on Climate Change: Climate Change 2007: The Physical Science Basis. Contribution of Working Group I to the Fourth Assessment Report of the Intergovernmental Panel on Climate Change, edited by: Solomon, S., Qin, D., Manning, M., Chen, Z., Marquis, M., Averyt, K. B., Tignor, M., and Miller, H. L., Cambridge Univ. Press, Cambridge, UK, 2007.

Jackson, C., Xia, Y., Sen, M. K., and Stoffa, P. L.: Optimal parameter and uncertainty estimation of a land surface model: A case study using data from Cabauw, Netherlands, J. Geophys. Res., 108, 4583, doi:10.1029/2002jd002991, 2003.

Jackson, C., Sen, M. K., and Stoffa, P. L.: An efficient stochastic Bayesian approach to optimal parameter and uncertainty estimation for climate model predictions, J. Climate, 17, 2828-2841, 2004.

Jackson, C. S., Sen, M. K., Huerta, G., Deng, Y., and Bowman, K. P.: Error Reduction and Convergence in Climate Prediction, J. Climate, 21, 6698-6709, doi:10.1175/2008jcli2112.1, 2008.

Janjic, Z. I.: The Step-Mountain Eta Coordinate Model - Further Developments of the Convection, Viscous Sublayer, and Turbulence Closure Schemes, Mon. Weather Rev., 122, 927-945, 1994.

Janjic, Z. I.: Nonsingular Implementation of the Mellor-Yamada Level 2.5 Scheme in the NCEP Meso model, NCEP Office Note, No. 437, 61 pp., 2002.

Johnson, R. H.: The role of convective-scale precipitation downdrafts in cumulus and synoptic-scale interactions, J. Atmos. Sci., 33, 1890-1910, 1976.

Kain, J. S.: The Kain-Fritsch convective parameterization: An update, J. Appl. Meteorol., 43, 170-181, 2004.

Kain, J. S. and Fritsch, J. M.: A One-Dimensional Entraining Detraining Plume Model and Its Application in Convective Parameterization, J. Atmos. Sci., 47, 2784-2802, 1990.

Kain, J. S. and Fritsch, J. M.: Convective parameterization for mesoscale models: The Kain-Fritcsh scheme, The representation of cumulus convection in numerical models, edited by: Emanuel, K. A. and Raymond, D. J., Amer. Meteor. Soc., Boston, USA, 246 pp., 1993.
Kain, J. S., Baldwin, M. E., Janish, P. R., and Weiss, S. J.: Utilizing the Eta model with two different convective parameterizations to predict convective initiation and evolution at the SPC, Preprints, Ninth Conference on Mesoscale Processes, Ft. Lauderdale, FL, 91-95, 2001.

Khairoutdinov, M. F. and Randall, D. A.: A cloud resolving model as a cloud parameterization in the NCAR Community Climate System Model: Preliminary results, Geophys. Res. Lett., 28, 3617-3620, 2001.

Kirkpatrick, S., Gelatt, C. D., and Vecchi, M. P.: Optimization by Simulated Annealing, Science, 220, 671-680, 1983.

Knupp, K. R. and Cotton, W. R.: Convective Cloud Downdraft Structure - an Interpretive Survey, Rev. Geophys., 23, 183-215, 1985.

Kreitzberg, C. W. and Perkey, D. J.: Release of Potential Instability .1. Sequential Plume Model within a Hydrostatic Primitive Equation Model, J. Atmos. Sci., 33, 456-475, 1976.

Liang, F.: Annealing evolutionary stochastic approximation Monte Carlo for global optimization, Stat. Comput., 21, 375-393, doi:10.1007/s11222-010-9176-1, 2010.

Liang, X.-Z., Li, L., Dai, A., and Kunkel, K. E.: Regional climate model simulation of summer precipitation diurnal cycle over the United States, Geophys. Res. Lett., 31, L24208, doi:10.1029/2004GL021054, 2004.

Liu, C. H., Moncrieff, M. W., and Grabowski, W. W.: Explicit and parameterized realizations of convective cloud systems in TOGA COARE, Mon. Weather Rev., 129, 1689-1703, 2001.

Lopez, A., Tebaldi, C., New, M., Stainforth, D., Allen, M., and Kettleborough, J.: Two approaches to quantifying uncertainty in global temperature changes, J. Climate, 19, 4785-4796, 2006.

Maurer, E. P., Wood, A. W., Adam, J. C., Lettenmaier, D. P., and Nijssen, B.: A long-term hydrologically based dataset of land surface fluxes and states for the conterminous United States, J. Climate, 15, 3237-3251, 2002.

Medeiros, B. and Stevens, B.: Revealing differences in GCM representations of low clouds, Climate Dynam., 36, 385-399, doi:10.1007/s00382-009-0694-5, 2011.

Metropolis, N., Rosenbluth, A. W., Rosenbluth, M. N., Teller, A. H., and Teller, E.: Equation of State Calculations by Fast Computing Machines, J. Chem. Phys., 21, 1087-1092, 1953.

Min, S. K., Simonis, D., and Hense, A.: Probabilistic climate change predictions applying Bayesian model averaging, Philos. T. Roy. Soc., 365A, 2103-2116, doi:10.1098/rsta.2007.2070, 2007.

Molders, N.: Plant- and soil-parameter-caused uncertainty of predicted surface fluxes, Mon. Weather Rev., 133, 3498-3516, 2005.

Morrison, H., Curry, J. A., and Khvorostyanov, V. I.: A new doublemoment microphysics parameterization for application in cloud and climate models. Part I: Description, J. Atmos. Sci., 62, 16651677, 2005.

Murphy, J. M., Sexton, D. M. H., Barnett, D. N., Jones, G. S., Webb, M. J., and Collins, M.: Quantification of modelling uncertainties in a large ensemble of climate change simulations, Nature, 430, 768-772, doi:10.1038/nature02771, 2004.

Murphy, J. M., Booth, B. B. B., Collins, M., Harris, G. R., Sexton, D. M. H., and Webb, M. J.: A methodology for probabilistic predictions of regional climate change from perturbed physics ensembles, Philos. T. Roy Soc., 365A, 1993-2028, doi:10.1098/rsta.2007.2077, 2007. 
Moskowitz, B. and Caflisch, R. E.: Smoothness and dimension reduction in quasi-Monte Carlo methods, Math Comput. Model, 23, 37-54, 1996.

Pincus, R., Barker, H. W., and Morcrette, J. J.: A fast, flexible, approximate technique for computing radiative transfer in inhomogeneous cloud fields, J. Geophys. Res., 108, 4376, doi:10.1029/2002JD003322, 2003.

Sen, M. K. and Stoffa, P. L.: Bayesian inference, Gibbs' sampler and uncertainty estimation in geophysical inversion, Geophys. Prospect., 44, 313-350, 1996.

Shepherd, J. M., Ferrier, B. S., and Ray, P. S.: Rainfall morphology in Florida convergence zones: A numerical study, Mon. Weather Rev., 129, 177-197, 2001.

Simpson, J. and Wiggert, V.: Models of Precipitating Cumulus Towers, Mon. Weather Rev., 97, 471-489, 1969.

Skamarock, W. C., Klemp, J. B., and Dudhia, J.: Prototypes for the WRF (Weather Research and Forecasting) model, Preprints, Ninth Conference on Mesoscale Processes, Amer. Met. Soc., Ft. Lauderdale, FL, J11-J15, 2001.

Skamarock, W. C., Klemp, J. B., Dudhia, J., Gill, D. O., Barker, D. M., Duda, M. G., Huang, X.-Y., Wang, W., and Powers, J. G.: A Description of the Advanced Research WRF Version 3, NCAR Technical Note, NCAR/TN-475+STR, 123 pp., 2008.

Stainforth, D. A., Aina, T., Christensen, C., Collins, M., Faull, N., Frame, D. J., Kettleborough, J. A., Knight, S., Martin, A., Murphy, J. M., Piani, C., Sexton, D., Smith, L. A., Spicer, R. A., Thorpe, A. J., and Allen, M. R.: Uncertainty in predictions of the climate response to rising levels of greenhouse gases, Nature, 433, 403-406, doi:10.1038/nature03301, 2005.

Stein, M.: Large Sample Properties of Simulations Using Latin Hypercube Sampling, Technometrics, 29, 143-151, 1987.

Tao, W. K., Chern, J. D., Atlas, R., Randall, D., Khairoutdinov, M., Li, J. L., Waliser, D. E., Hou, A., Lin, X., Peters-Lidard, C., Lau, W., Jiang, J., and Simpson, J.: A Multiscale Modeling System Developments, Applications, and Critical Issues, B. Am. Meteorol. Soc., 90, 515-534, doi:10.1175/2008bams2542.1, 2009.
Taylor, K. E.: Summarizing multiple aspects of model performance in single diagram, J. Geophys. Res., 106, 7183-7192, doi:10.1029/2000JD900719, 2001.

Tebaldi, C., Smith, R. L., Nychka, D., and Mearns, L. O.: Quantifying uncertainty in projections of regional climate change: A Bayesian approach to the analysis of multimodel ensembles, J. Climate, 18, 1524-1540, 2005.

Tierney, L. and Mira, A.: Some adaptive Monte Carlo methods for Bayesian inference, Stat. Med., 18, 2507-2515, 1999.

Villagran, A., Huerta, G., Jackson, C. S., and Sen, M. K.: Computational Methods for Parameter Estimation in Climate Models, Bayesian Analysis, 3, 823-850, doi:10.1214/08-BA331, 2008.

Warner, T. T. and Hsu, H. M.: Nested-model simulation of moist convection: The impact of coarse-grid parameterized convection on fine-grid resolved convection, Mon. Weather Rev., 128, 2211 2231, 2000.

Webb, M. J., Senior, C. A., Sexton, D. M. H., Ingram, W. J., Williams, K. D., Ringer, M. A., McAvaney, B. J., Colman, R., Soden, B. J., Gudgel, R., Knutson, T., Emori, S., Ogura, T., Tsushima, Y., Andronova, N., Li, B., Musat, I., Bony, S., and Taylor, K. E.: On the contribution of local feedback mechanisms to the range of climate sensitivity in two GCM ensembles, Clim Dynam., 27, 17-38, doi:10.1007/s00382-006-0111-2, 2006.

Zhang, G. J. and McFarlane, N. A.: Sensitivity of Climate Simulations to the Parameterization of Cumulus Convection in the Canadian Climate Center General-Circulation Model, Atmos. Ocean, 33, 407-446, 1995. 